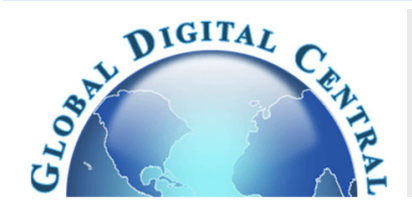

Frontiers in Heat and Mass Transfer

Available at www.ThermalFluidsCentral.org

\title{
A NUMERICAL AND EXPERIMENTAL STUDY OF THE EFFECT OF USING PERSONAL VENTILATION SYSTEMS ON INDOOR AIR QUALITY IN OFFICE ROOMS
}

\author{
Hussien Aziz Saheb ${ }^{*}$ Ala'a Abbas Mahdi, Qusay Rasheed Al-amir \\ Mechanical Engineering Department, University of Babylon, Iraq
}

\begin{abstract}
In this study, indoor air quality and thermal comfort were investigated for two persons sitting inside an office room of dimensions $(3 \times 2.5 \times 2.5 \mathrm{~m})$. The office room is equipped with personal ventilation systems positioned $50 \mathrm{~cm}$ from the person's face. These systems are characterized by the ability to change the rates of airflow (ATD). Experimental studies and results were conducted on a thermal manikin that simulates the human body in a sitting position, and the results are compared with CFD analysis using the k-epsilon and the RNG turbulent models. The experimental study focused on measuring the speed and temperature of the air in different areas inside the room, as well as measuring it around the thermal manikin and in the breathing zone. In the numerical analysis, the thermal comfort and the indoor air quality and the detailed airflow around the occupants were evaluated using CFD analysis. It has been found that the use of personal ventilation systems increases thermal comfort and indoor air quality. It was found that by maintaining the temperature of the supply air from the personal ventilation system and increasing the speed of the air supply, this leads to a decrease in the temperature of the breathing air, an increase in the quality of the inhaled air, as well as a lowering of the person's temperature.
\end{abstract}

Keywords: Thermal comfort, AIRPAK, Computational fluid-dynamics (CFD), Mixing ventilation (MV), Indoor air quality (IAQ), Personalized ventilation $(P V)$.

\section{INTRODUCTION}

Nowadays, the work and activity of people are mostly inside closed environments such as factories, workshops, laboratories, and offices, most of which need ventilation systems for maintaining indoor air quality and avoiding problems of poor ventilation. All recent research has focused on how the thermal environment affects human comfort and performance (Zeng and Rongyi, 2005). Mixing ventilation systems are known as traditional ventilation systems that provide fresh, cold air at high speed, as it is supplied from the top of the room through an air diffuser located outside the occupied zone. The high air velocity ensures a uniform distribution of pollutants and temperatures inside the room (Awbi, 2017). The main problems that defect traditional ventilation systems, such as mixing ventilation systems and displacement ventilation systems, is that the supply air from outside the room mixes with the polluted air inside the room before reaching the breathing zone( Melikov, 2004 ). The personal ventilation systems have been used to supply cold and fresh air directly to the breathing zone, which improves the quality of the inhaled air and thermal comfort (Kaczmarczyk et al., 2004). Personal ventilation systems provide individual control over air temperature, direction and speed, and can protect space occupants from airborne infectious diseases (Cermak et al. 2006 and Peter et al., 2007) The personal ventilation systems target the occupant breathing zone, the interaction between the supplied air and the flow in the delicate environment surrounding the occupant is the determining factor for personal ventilation systems performance (Melikov, 2015). Many practical experiments were conducted to study the perceived air quality, and its improvement was observed significantly in the case of the use of personal ventilation systems. A significant improvement was also recorded in the indoor air quality, and the thermal comfort for each person was increased by allowing the provision of the local environment for each occupant separately, as well as a reduction of SBS symptoms (Kroner, 1994, Olesen 2007 and Chen, 2014). The experimental and numerical studies was conducted by a group of researchers such as (Elmaghraby 2014 and Mohammed 2013), where those studies were conducted to investigate the patterns of air distribution, temperature distribution, air velocity, pollutant distribution, and concentration inside rooms in the case of using personal ventilation systems with traditional ventilation systems such as mixing ventilation systems.

Al-ssaad et al. (2017) investigated the improvement of ventilation by combining personal ventilation with mixing ventilation. The study was carried out numerically and experimentally, At ideal conditions, a thermal comfort about 0.95 and also ventilation effectiveness $77 \%$ was obtained, the cost of energy for PV system was reduced by $21.34 \%$ compared to a constant personal ventilation system at equal thermal comfort. This study demonstrated that the RNG k- $\varepsilon$ model with enhanced wall treatment is used to model turbulence. It is characterized by accuracy and very good predictability of jet spreading rate and the behavior of re-circulated air.

Al-ssaad et al. (2018) studied the best performance of an MV system Compound with PV, and Simulated were performed using the CFD technique to find out the airflow the most suitable supply frequency, Fresh air is emitted from (PV) towards the upper part of the person. The purpose of this study was to achieve good thermal comfort and good IAQ in the breathing zone. In this study, the test model was simulated numerically using CFD technology, with a transient 3D test under laboratory conditions at a temperature of $25^{\circ} \mathrm{C}$ and a PV jet temperature 
of $22^{\circ} \mathrm{C}$. This study showed that when the frequency increases at a constant flow rate, thermal comfort increased by $15.2 \%$. However, when the medium flow rate increased at a fixed frequency, thermal comfort decreased at a low frequency of $0.3 \mathrm{~Hz}$ but remained acceptable at a higher frequency of $0.5 \mathrm{~Hz}$.

Hooff and Blocken (2019) introduced MV driven by two oppositely located supply jets with a time-periodic supply speed, theoretical analysis using (CFD) program. The temperature of the air in the small office, with a higher cooling load, so it was chosen the change of air rate carefully to avoid a higher temperature gradient. This study showed that the use of the turbulence model (RNG $\mathrm{k}-\varepsilon$ ) gave excellent and accurate results as well as the ability to predict well on jet spreading rate and the behavior of recirculating air.

Yakoob et al. (2019) studied personal ventilation with displacement ventilation (DV) for the purpose evaluated the efficiency of air exchange in rooms. The study was practical and theoretical, this study using RNG, $\mathrm{K}-\varepsilon$ turbulence model for simulating temperature profile. This study concluded, that the arrangements at an office room for the air supply diffuser personal and DV are combined Acceptable human thermal comfort depending on the value of (Et) and (ADPI) which gives (71\%) and (1.8) respectively which improved the air quality and thermal comfort.

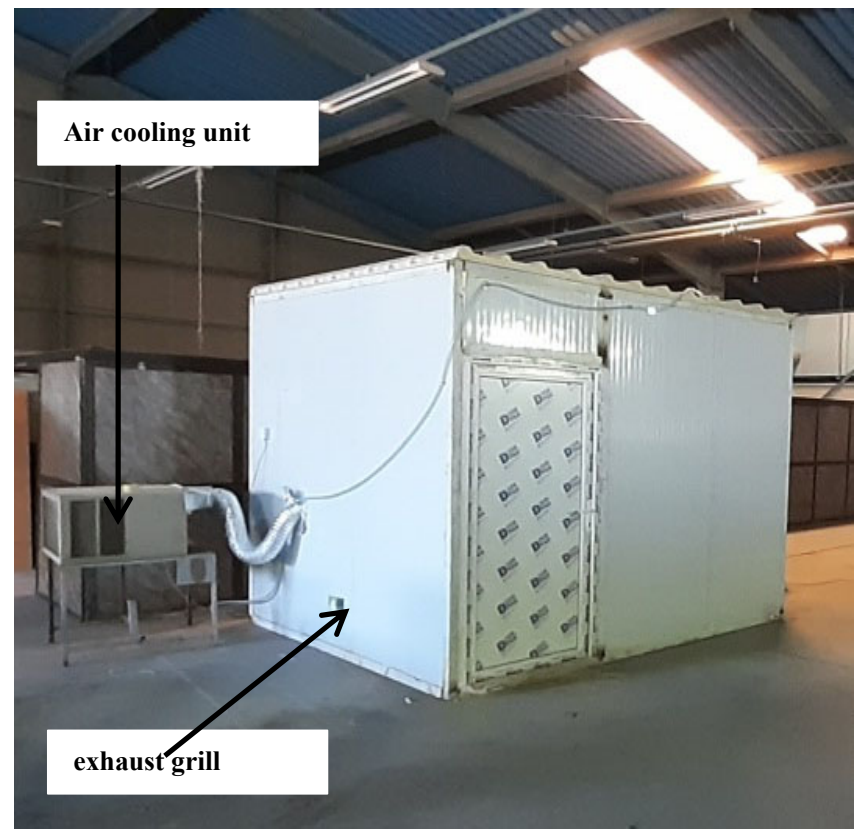

Fig. 1 Thermally insulated test chamber
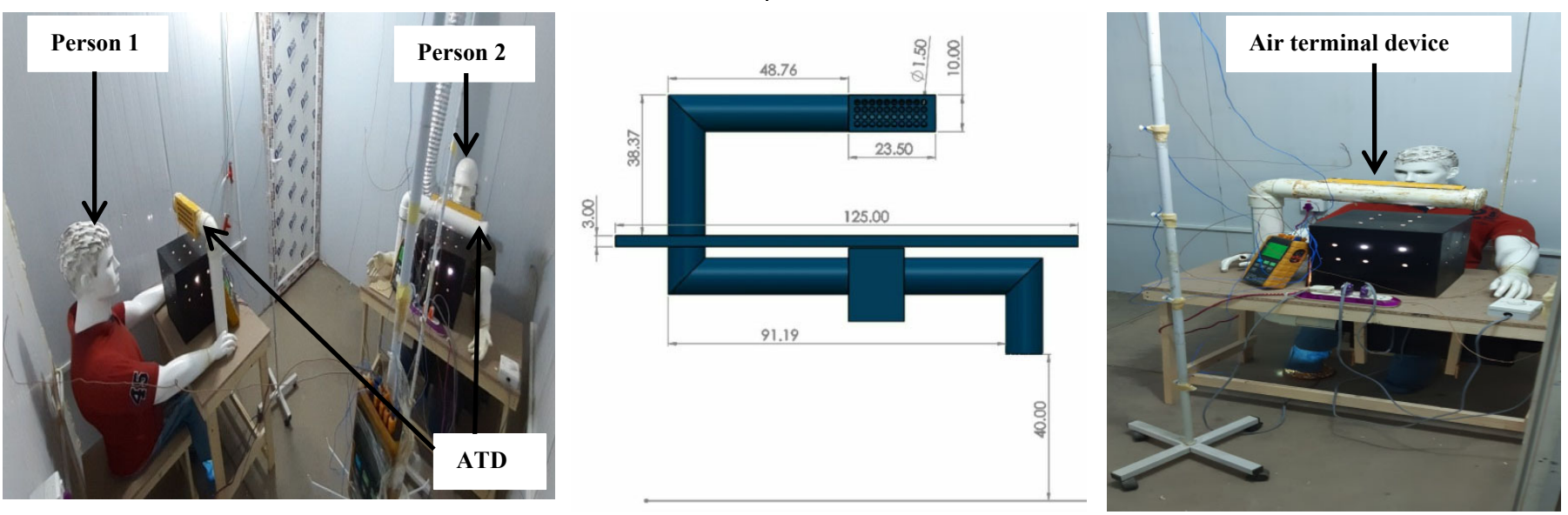

Fig. 3 Thermally insulated test chamber, caseII

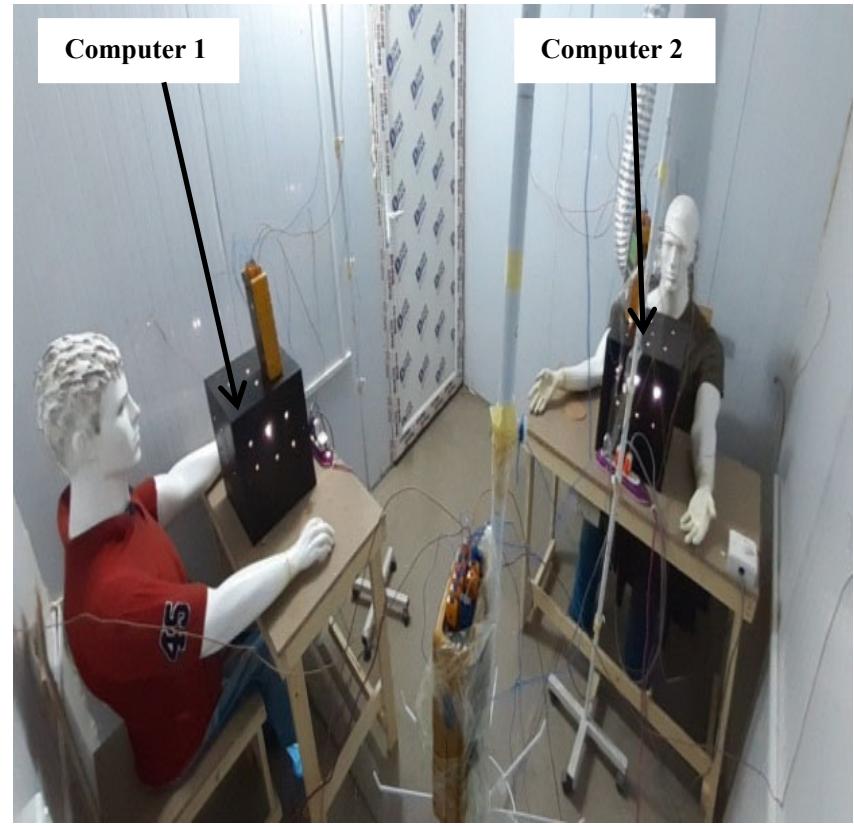

Fig. 2 Thermally insulated test chamber, case I

Fig. 4 Personal ventilation system 

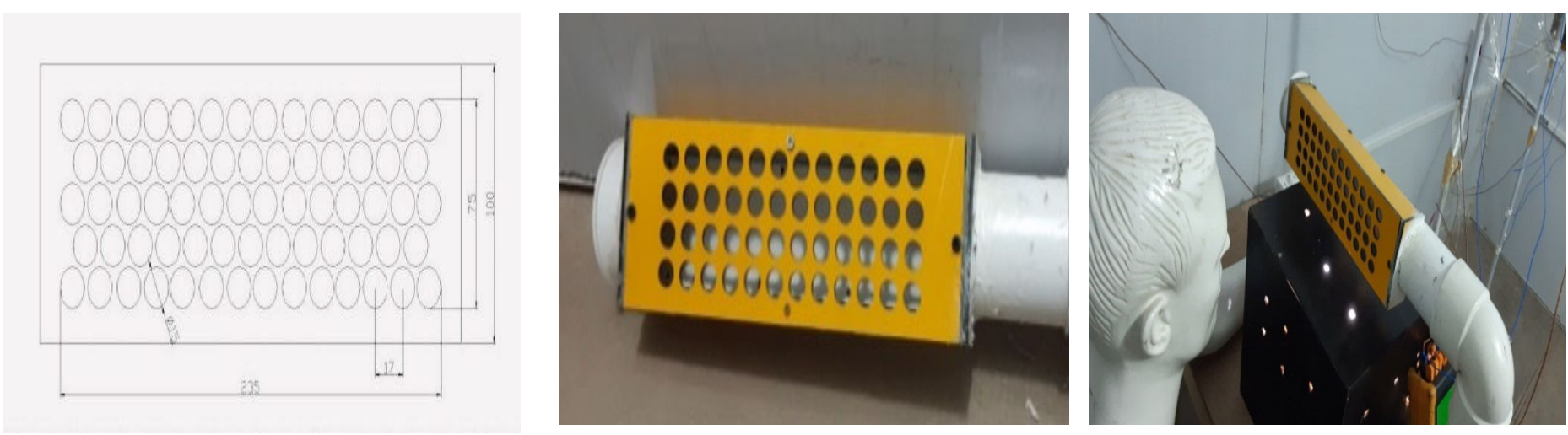

Fig. 5 Air terminal device

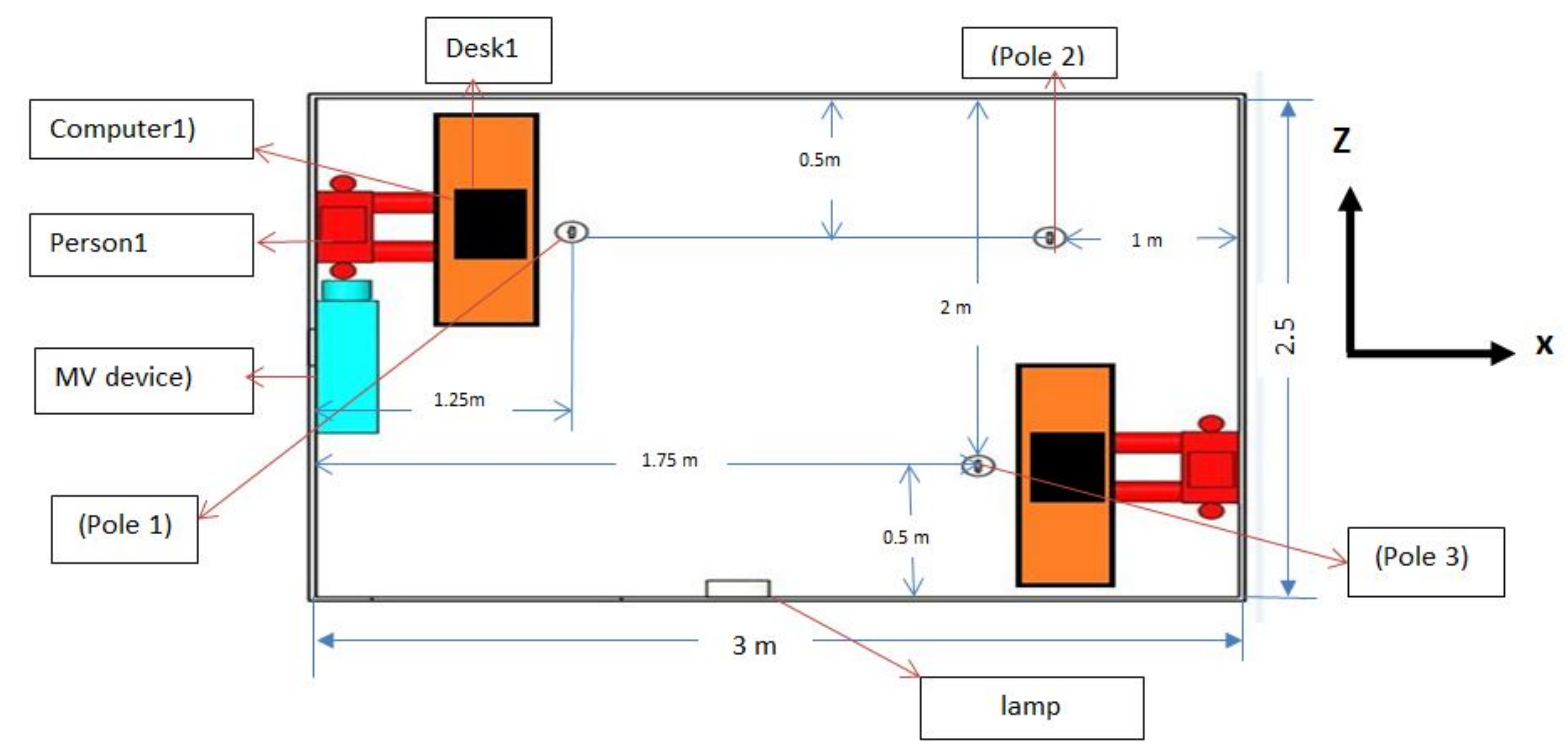

Fig. 6 poles were used to install thermocouples in different places top view

Table 1 room configuration for MV only, for thermally insulated room

\begin{tabular}{|c|c|c|c|c|c|c|c|}
\hline \multirow{3}{*}{ Item } & \multicolumn{6}{|c|}{ Location $(m)$} & \multirow{3}{*}{ Heat(W) (Awbi, 2003) } \\
\hline & \multicolumn{3}{|c|}{ start } & \multicolumn{3}{|c|}{ end } & \\
\hline & $X$ & $Y$ & $Z$ & $X$ & $Y$ & $Z$ & \\
\hline Room & 0 & 0 & 0 & 3 & 2.5 & 2.5 & \\
\hline Mixing device & 0 & 2.1 & 1.15 & 0.1 & 2.2 & 1.35 & \\
\hline Exhaust grille & 0 & 0.3 & 1.17 & 0 & 0.4 & 1.33 & \\
\hline Person no.1 & 0.15 & 0 & 0.3 & 0.35 & 1.1 & 0.7 & 75 \\
\hline Person no. 2 & 2.65 & 0 & 1.8 & 2.85 & 1.1 & 2.2 & 75 \\
\hline Computer_no.1 & 0.6 & 0.76 & 0.35 & 0.9 & 1.06 & 0.65 & 60 \\
\hline Computer_no.2 & 2.1 & 0.76 & 1.85 & 2.4 & 1.06 & 2.15 & 60 \\
\hline Light & 1.45 & 2.4 & 2.3 & 1.55 & 2.45 & 2.5 & 100 \\
\hline Computer table1 & 0.5 & 0.76 & 0 & 1 & 0 & 1 & \\
\hline Computer table 2 & 2 & 0.76 & 1.5 & 2.5 & 0 & 2.5 & \\
\hline
\end{tabular}


Table 2 room configuration for MV combined with PV system for Thermally insulated room

\begin{tabular}{|c|c|c|c|c|c|c|c|}
\hline \multirow{3}{*}{ Item } & \multicolumn{6}{|c|}{ Location $(m)$} & \multirow{3}{*}{$\operatorname{Heat}(W)(A w b i, 2003)$} \\
\hline & \multicolumn{3}{|c|}{ start } & \multicolumn{3}{|c|}{ end } & \\
\hline & $X$ & $Y$ & $Z$ & $X$ & $Y$ & $Z$ & \\
\hline Room & 0 & 0 & 0 & 3 & 2.5 & 2.5 & \\
\hline Mixing device & 0 & 2.1 & 1.15 & 0.1 & 2.2 & 1.35 & \\
\hline Exhaust grille & 0 & 0.3 & 1.17 & 0 & 0.4 & 1.33 & \\
\hline Person no.1 & 0.15 & 0 & 0.3 & 0.35 & 1.1 & 0.7 & 75 \\
\hline Person no. 2 & 2.65 & 0 & 1.8 & 2.85 & 1.1 & 2.2 & 75 \\
\hline Computer_no.1 & 0.6 & 0.76 & 0.35 & 0.9 & 1.06 & 0.65 & 60 \\
\hline Computer_no.2 & 2.1 & 0.76 & 1.85 & 2.4 & 1.06 & 2.15 & 60 \\
\hline Light & 1.45 & 2.4 & 2.3 & 1.55 & 2.45 & 2.5 & 100 \\
\hline Computer tablel & 0.5 & 0.76 & 0 & 1 & 0 & 1 & \\
\hline Computer table 2 & 2 & 0.76 & 1.5 & 2.5 & 0 & 2.5 & \\
\hline Personal devicel & 0.6 & 1.05 & 0.38 & 0.7 & 1.1 & 0.62 & \\
\hline Personal device2 & 2.2 & 1.05 & 1.88 & 2.3 & 1.1 & 2.12 & \\
\hline
\end{tabular}

Katramiz et al. (2020) studied the interaction between breathing of human and the intermittent personalized ventilation (IPV) jet and investigated the effectiveness of IPV in supplying fresh and cold air of breathable. The results of this study gave that maximum effectiveness of ventilation during inhalation was obtained at an intermittent personalized ventilation (IPV) frequency of $0.5 \mathrm{~Hz}$ ranging from $36.75 \%$ to $86.6 \%$ for breathing through the nose, $49.6 \%$ to $87.3 \%$ for breathing through the mouth. The use of intermittent personal ventilation system improves the quality of air in the breathing zone (BZ).

Zhao et al. (2021) studied the performance of a micro-environment system combined radiant panel and convective flow was designed and compared to an all-air diffuse ceiling ventilation (DCV) system. In the analyzed micro-environment system of personalized ventilation and radiant panel (PVRP), two local personal air terminal devices supplied clean air directly to occupants. The radiant panels were used to satisfy the required cooling load. The results show that the air change efficiency with the PVRP was over $60 \%$ which was better than the fully mixing flow $(50 \%)$. The mean age of air of personalized airflow system was smaller at the micro-environment near the workstation than the DCV despite the airflow rate was much lower. Furthermore, the air temperature near the workstation can be maintained at designed value with the PVRP and the draught rate can be kept at acceptable level. Furthermore, the vertical temperature difference did not cause thermal discomfort with the PVRP system near the workstation.

The main objectives of this study are:

1- The current work aims to study the effect of the use of personal ventilation systems on indoor air quality and thermal comfort of occupants

2- This study targets person's breathing zone and how to improve the quality of inhaled air when using personal ventilation systems Study the effect of personal ventilation systems on thermal comfort

3- Calculating the amount of air to be supplied to the room and the temperature of the supply air required for providing suitable environmental conditions for persons.

4- Investigation of indoor air quality and thermal comfort by numerically computing ADPI and effectiveness of ventilation using CFD modeling

5- To check the possibility of using personal ventilation systems with mixing ventilation systems inside office rooms in hot and dry climates.

6- Comparing the experimental results with the numerical results and indicating the accuracy of those results after comparing them with experiments conducted on real persons.

\section{EXPERIMENTAL METHOD}

A thermally insulated room with dimensions of $(3 \times 2.5 \times 2.5 \mathrm{~m})$ made of (Sandwich panel) material was used. These experiments were conducted in the laboratories of the Faculty of Engineering at the University of Babylon in the Iraqi city of Babylon. Steady-state working conditions were assumed in both experimental and numerical analysis. In practical experiments, the temperature distribution and air velocity around people and inside the room were calculated, and the rates of airflow, speed, and temperature were calculated at (ATD) and at the air diffuser (MV device). Two types of experiments were conducted, depending on the types of ventilation systems used, so the first type was based on MV systems only, and the second type of experiment was based on PV systems with mixing ventilation systems. The test room contained different heat sources, including one light lump (100 watts), and two thermal manikins were used, which were placed to simulate the human body, as they generate sensible heat ( 75 watts) for each thermal manikin as well as two boxes containing heat sources were placed inside them to simulate computers (60 Watts) for each one as shown in Figs (1),(2), and(3), distribution and locations of persons and room contents for the two cases, as shown in tables (1) and (2) respectively. Commercial airconditioner was used to deliver the cooled air to the indoor space of the room. Also, PV system consists of a fan with different flow rates controlled by an electric regulator where the air is pushed from the bottom at $0.4 \mathrm{~m}$ through air terminal device (ATD) to the top at the human seating level of $1.1 \mathrm{~m}$ as shown in Fig(4), and(5). In the experimental practical side, a group of devices and equipment used in the field of ventilation experiments were used, such as temperature measuring devices (K-type thermocouples), as well as the hot wire type (YK.2005AH) to measure air velocity, as poles were used to install thermocouples in different places inside a room as shown in Fig (6).

\section{A. Supply System:}

A set of experiments were conducted in a thermally isolated room in a laboratory with conditions of $25^{\circ} \mathrm{C}$ and a pressure of one bar. Therefore, the room temperature before the experiment was $25^{\circ} \mathrm{C}$. The air was supplied at speed from 2.5 to $8 \mathrm{~m} / \mathrm{s}$ and temperatures from $15^{\circ} \mathrm{C}$ to $22^{\circ} \mathrm{C}$. Through experiments and results. It was found that the best speed and temperature of the supply air from the diffuser were $2.5 \mathrm{~m} / \mathrm{s}$ and $17^{\circ} \mathrm{C}$.

The temperature of the thermally insulated room was calculated and found to be $25{ }^{\circ} \mathrm{C}$. Air is the supposed working fluid, and the flow is assumed to be steady-state, $3 \mathrm{D}$ flow and incompressible. The tested room was thermally insulated, so the values of $\left(\mathrm{q}_{1} \& \mathrm{q}_{\mathrm{ex}}\right)$ are equal to zero in this work. 
The following two steps are used to estimate the supply ventilation rate for MV system and total heat applications (Awbi, 2007). The necessary air volume is calculated (airflow rate), The heat transfer due to the ventilation process is calculated by the following equations which are illustrated as,

$$
\mathrm{Q}_{\mathrm{t}}=\dot{\mathrm{m}} \times c p \times \Delta T
$$

$$
\mathrm{Q}_{\mathrm{t}}=\mathrm{q}_{\mathrm{oe}}+\mathrm{q}_{\mathrm{l}}+\mathrm{q}_{\mathrm{ex}}
$$

From the value of the mass flow rate $\dot{m}$ in the above equations can be calculated design airflow rate $(1 / \mathrm{s})$

$$
\mathrm{Q}_{\mathrm{s}}=\frac{\dot{\mathrm{m}}}{\rho}
$$

The air was supplied at speed at $2.5 \mathrm{~m} / \mathrm{s}$. After using the equation (3), the cross-sectional area of the air diffuser was calculated.

\section{B. Experimental Procedures:}

A set of experiments were conducted in July 2020, and there were two types of experiments, depending on the type of ventilation system used. The first type included the use of MV systems only. The second type used the PV system with the MV system. After two hours of operating mode and reaching almost steady-state, all readings related to ventilation in terms of temperature distribution and air velocity inside the room were taken, as each experiment was repeated five times and an average of the readings was taken to reach the most accurate results. In the second case, an air flow rate from (ATD) at 5 to $71 / \mathrm{s}$ was used.

$$
\mathrm{Q}_{\mathrm{s}}=\mathrm{U}_{\mathrm{x}} \times \mathrm{A}_{\mathrm{s}}
$$

Where: $U_{x}$ : local airspeed $(\mathrm{m} / \mathrm{s})$, As Surface area of supply air diffuser $\left(\mathrm{m}^{2}\right)$. Then $\mathrm{As}_{\mathrm{s}}=0.04 / 2.5=0.016 \mathrm{~m}^{2}$.

\section{ANALYTICAL INVESTIGATION}

In the current work, according to CFD simulation, the flow was assumed to be steady, 3D, Newtonian, incompressible fluid, without chemical reaction, and turbulent flow fluid, ideal fluid and frictionless (Awbi, 2007).

\section{A. General Governing Conservation Equations:}

$\frac{\partial}{\partial x}(\rho u)+\frac{\partial}{\partial y}(\rho v)+\frac{\partial}{\partial z}(\rho w)=0$

$$
\begin{aligned}
& \frac{\partial}{\partial x}(\rho u u)+\frac{\partial}{\partial y}(\rho u v)+\frac{\partial}{\partial z}(\rho u w) \\
& =-\frac{\partial p}{\partial x}+\frac{\partial}{\partial x}\left(\mu \frac{\partial u}{\partial x}\right)+\frac{\partial}{\partial y}\left(\mu \frac{\partial u}{\partial y}\right)+\frac{\partial}{\partial z} \\
& \left(\mu \frac{\partial \mathrm{u}}{\partial \mathrm{z}}\right)+\frac{1}{3} \frac{\partial}{\partial \mathrm{x}}\left[\mu\left(\frac{\partial \mathrm{u}}{\partial \mathrm{x}}+\frac{\partial \mathrm{v}}{\partial \mathrm{y}}+\frac{\partial \mathrm{w}}{\partial \mathrm{z}}\right)\right]+\frac{\partial}{\partial x}\left(-\rho \overline{u^{\prime} u^{\prime}}\right)+ \\
& \frac{\partial}{\partial y}\left(-\rho \overline{u^{\prime} v^{\prime}}\right)+\frac{\partial}{\partial z}\left(-\rho \overline{u^{\prime} w^{\prime}}\right)+\rho g_{x}
\end{aligned}
$$

$$
\frac{\partial}{\partial x}(\rho u v)+\frac{\partial}{\partial y}(\rho v v)+\frac{\partial}{\partial z}(\rho v w)=-\frac{\partial p}{\partial y}+\frac{\partial}{\partial x}\left(\mu \frac{\partial v}{\partial x}\right)+
$$$$
\frac{\partial}{\partial y}\left(\mu \frac{\partial v}{\partial y}\right)+\frac{\partial}{\partial z}
$$$$
\left(\mu \frac{\partial \mathrm{v}}{\partial \mathrm{z}}\right)+\frac{1}{3} \frac{\partial}{\partial \mathrm{y}}\left[\mu\left(\frac{\partial \mathrm{u}}{\partial \mathrm{x}}+\frac{\partial \mathrm{v}}{\partial \mathrm{y}}+\frac{\partial \mathrm{w}}{\partial \mathrm{z}}\right)\right]+\frac{\partial}{\partial x}\left(-\rho \overline{u^{\prime} v^{\prime}}\right)+
$$$$
\frac{\partial}{\partial y}\left(-\rho \overline{v^{\prime} v^{\prime}}\right)+\frac{\partial}{\partial z}\left(-\rho \overline{v^{\prime} w^{\prime}}\right)+\rho g_{y}
$$

$\frac{\partial}{\partial \mathrm{x}}(\rho \mathrm{uw})+\frac{\partial}{\partial \mathrm{y}}(\rho \mathrm{vw})+\frac{\partial}{\partial \mathrm{z}}(\rho \mathrm{ww})=-\frac{\partial \mathrm{p}}{\partial \mathrm{z}}+\frac{\partial}{\partial \mathrm{x}}\left(\mu \frac{\partial \mathrm{w}}{\partial \mathrm{x}}\right)+$ $\frac{\partial}{\partial y}\left(\mu \frac{\partial w}{\partial y}\right)+\frac{\partial}{\partial z}\left(\mu \frac{\partial w}{\partial z}\right)+\frac{1}{3} \frac{\partial}{\partial z}\left[\mu\left(\frac{\partial u}{\partial x}+\frac{\partial v}{\partial y}+\frac{\partial w}{\partial z}\right)\right]+$

$\frac{\partial}{\partial x}\left(-\rho \overline{u^{\prime} w^{\prime}}\right)+\frac{\partial}{\partial y}\left(-\rho \overline{v^{\prime} w^{\prime}}\right)+\frac{\partial}{\partial z}\left(-\rho \overline{w^{\prime} w^{\prime}}\right)+\rho g_{z}$

$\frac{\partial}{\partial \mathrm{x}}(\rho \mathrm{ut})+\frac{\partial}{\partial \mathrm{y}}(\rho \mathrm{vt})+\frac{\partial}{\partial \mathrm{z}}(\rho \mathrm{wt})=\frac{\partial}{\partial \mathrm{x}}\left(\Gamma \frac{\partial \mathrm{t}}{\partial \mathrm{x}}\right)+\frac{\partial}{\partial \mathrm{y}}\left(\Gamma \frac{\partial \mathrm{t}}{\partial \mathrm{y}}\right)+$

$\frac{\partial}{\partial \mathrm{z}}\left(\Gamma \frac{\partial \mathrm{t}}{\partial \mathrm{z}}\right)+\frac{\partial}{\partial \mathrm{x}}\left(-\rho \overline{\mathrm{u}^{\prime} \mathrm{t}^{\prime}}\right)+\frac{\partial}{\partial \mathrm{y}}\left(-\rho \overline{\mathrm{v}^{\prime} \mathrm{t}^{\prime}}\right)+\frac{\partial}{\partial \mathrm{z}}\left(-\rho \overline{\mathrm{w}^{\prime} \mathrm{t}^{\prime}}\right)+$

$\mathrm{S}_{\mathrm{t}}$

where: $(\Gamma)$ is the coefficient of diffusion, which is given by $\Gamma=\frac{\mu}{\sigma},(\sigma=$ $\mu \times \mathrm{C}_{\mathrm{p}} / \mathrm{Y}$ ) is the Prandtl or Schmidt number for the fluid. The terms $-\rho \overline{\mathrm{u}^{\prime} \mathrm{t}^{\prime}},-\rho \overline{\mathrm{v}^{\prime} \mathrm{t}^{\prime}}$ and $-\rho \overline{\mathrm{w}^{\prime} \mathrm{t}^{\prime}}$ Are the turbulent heat fluxes, St is a source term allowing for the rate of thermal energy production.

\section{B. Computational Set and Numerical Scheme}

Boundary conditions in fluid dynamics are the set of constraints to boundary value problems in computational fluid dynamics. These boundary conditions include inlet boundary conditions, outlet boundary conditions, wall boundary conditions, constant pressure boundary conditions, axisymmetric boundary conditions, symmetric boundary conditions, and periodic or cyclic boundary conditions as shown Table 3 . When the problem is solving numerically, it is impossible to get an exact solution, Therefore accepted scaled residuals of error must be specified for different terms such as continuity, components of speed, and energy . Finally, the temperature of the air was simulated using the turbulent model RNG K-epsilon . In addition to the measurement of the Heat removal effectiveness $\left(\varepsilon_{\mathrm{t}}\right)$, a simulation was performed to calculate the ADPI of the ventilation of the office room While using the software system (CFD). Airpak simulation software has been widely applied to numerical simulation based on the limited size method, Airpak uses the FLUENT CFD engine to solve thermal calculations and flow of fluid to solve the equation to conserve mass, energy, and air momentum. RNG, $\mathrm{K}-\varepsilon$ turbulence model was chosen to solve flow equations. In this study, the cells number was found (440145)for MV, and(482985)for PMV, while using Hexa unstructured geometry to discretize. For this function, all types of elements were used to fit the grid to the geometry. Simulations were repeated to a level of approximation $10^{-3}$ until the solutions were stable, as shown in the figure. (7). Also, a mesh improvement study was conducted to identify and reduce the error due to the estimate. Four different mesh systems were coarser type, course type, medium type, and fine were generated, to perform the test (Jassim et al., 2019). The AIRPAK3.0.16 software was used to create the model, and meshed study cases based on several testing meshes as shown in Figures 8 , the dimensions of room edges in $(\mathrm{x}, \mathrm{y}, \mathrm{z})$ meshed as interval size of (0.04), mesh parameter normal, with Max side ratio (2), The selection was made after several attempts. After applying the meshing strategy as shown table(4).

Table 3: Boundary Conditions

\begin{tabular}{|c|c|l|}
\hline part & type & $\begin{array}{c}\text { Condition of } \\
\text { momentum }\end{array}$ \\
\hline $\begin{array}{c}\text { Persons, computers, } \\
\text { floor, side wall, ceil, } \\
\text { table, light, }\end{array}$ & wall & $\begin{array}{l}\text { Stationary, No } \\
\text { Slipping }\end{array}$ \\
\hline Extract Grill & $\begin{array}{c}\text { Pressure } \\
\text { outlet }\end{array}$ & Gauge Pressure $=(0$ \\
\hline
\end{tabular}




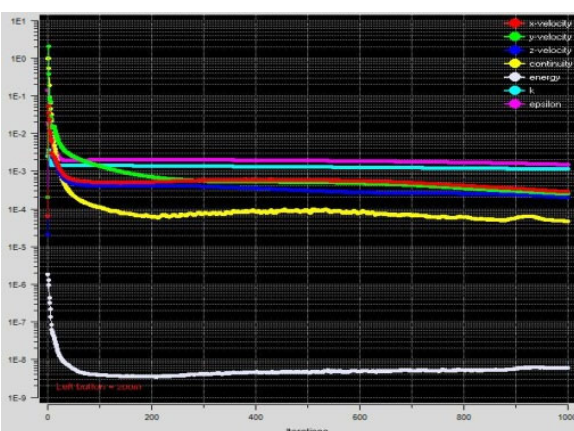

Fig. 7 Residuals Plot
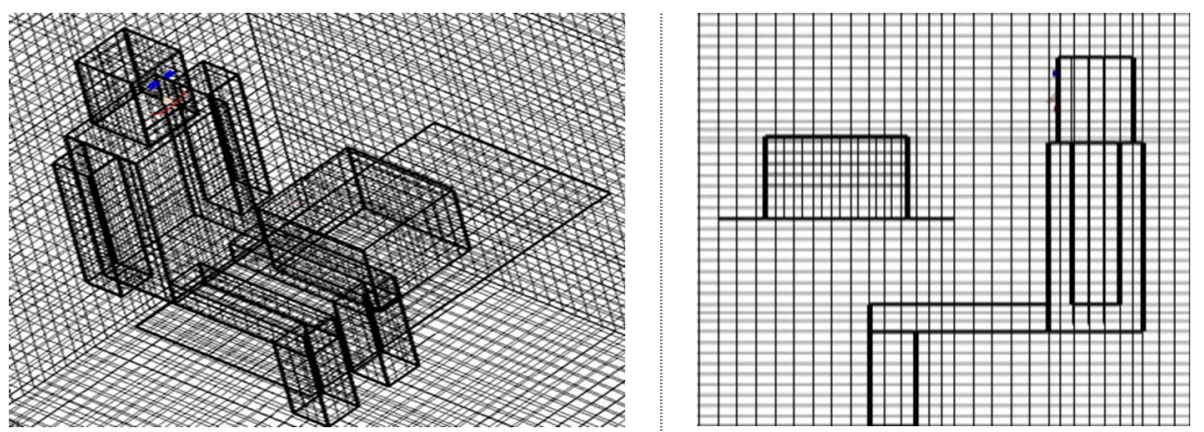

Fig. 8 part from meshed model
Table 4: Grid independence for average mean temperature

\begin{tabular}{|c|c|c|c|}
\hline \multirow{2}{*}{ No } & \multicolumn{3}{|c|}{ Table 4 Mesh testing for average mean temperature } \\
\cline { 2 - 4 } & Size element & No of Nodes & $\begin{array}{c}\text { Mean } \\
\text { temperature }\end{array}$ \\
\hline 1 & 0.06 & 449856 & 26.45 \\
\hline 2 & 0.05 & 456741 & 25.21 \\
\hline 3 & 0.04 & 459817 & 24.74 \\
\hline 4 & 0.03 & 461453 & 24.72 \\
\hline 5 & 0.02 & 468455 & 24.71 \\
\hline
\end{tabular}

When solving problem numerically it's impossible to get an exact solution, so accepted scaled error residuals should be specified for different terms such as continuity, velocity components and energy. In this Distribution Performance Index (ADPI) was evaluated to assessment diffusion performance of air for different cases in a ventilated space. The validation was carried out by comparing obtained CFD results with data obtained from experiments in tested room for case-I and case-II (mixing and personal ventilation system). The comparison depends on the vertical temperature which measured in tested room in six levels and that of numerical studies. The overall average error calculations due to the following equation

$E=(1 / n) \sum_{i=1}^{n} \frac{\left|X_{C F D}^{i}-X_{E X P}^{i}\right|}{X_{E X P}^{i}}$

\section{RESULTS AND DISCUSSION}

\section{Experimental Results}

\section{Analysis of temperature distribution and air velocity}

The diffuser provides air at high speed, MV device installed at the middle of the north side wall, where the speed and temperature of the air supplied by the diffuser at $2.5 \mathrm{~m} / \mathrm{s}$ and $17^{\circ} \mathrm{C}$ respectively. Three poles were used inside the room, and the temperature was measured at six different heights in each pole from $0 \mathrm{~m}$ to $1.8 \mathrm{~m}$, the Fig. (9) shows the relationship between the temperature of air and the height for three poles. The air temperature was measured at different altitudes, as shown in the Table 5.

Table 5 Experimental results of MV systems for case (I)

\begin{tabular}{|l|l|l|l|}
\hline \multirow{2}{*}{$\begin{array}{l}\text { Height } \\
(\mathrm{m})\end{array}$} & Pole 1 & Pole 2 & Pole 3 \\
\cline { 2 - 4 } & Temperature ${ }^{\circ} \mathrm{C}$ & Temperature ${ }^{\circ} \mathrm{C}$ & Temperature ${ }^{\circ} \mathrm{C}$ \\
\hline 0 & 26.856 & 25.647 & 26.745 \\
\hline 0.4 & 25.645 & 24.563 & 25.123 \\
\hline 0.8 & 27.45 & 26.453 & 26.87 \\
\hline 1.1 & 27.86 & 26.8 & 27 \\
\hline 1.4 & 26.45 & 25.46 & 26.121 \\
\hline 1.8 & 25.723 & 24.845 & 25.12 \\
\hline
\end{tabular}

Through experimental results, there is a uniform temperature distribution. The floor temperature is not the lowest temperature inside the test room, but the lowest measured temperatures were at the height of
$0.4 \mathrm{~m}$ above the floor of the room. The reason for the uniform temperature distribution inside the room is because the air is supplied with high speed and momentum. Thus, the movement of air molecules does not depend on the difference in densities between hot and cold air. It is noticed that the air temperature is lower in the upper levels of the room due to the supply of cold air. At the lower levels, the measured temperature is slightly higher due to the heat sources inside the room and then begins to decrease with increases in the height from the floor due to the presence of an air distributor. Fig. (9), the temperature increased with the increase in height from $(0.4$ to 1.1$) \mathrm{m}$, as a result of the heat gains resulting from the sources of heat inside the room, thermal plumes raised to the top where the hot air is less dense than cold air. The air temperature begins to drop again due to the preparation of cold air close to the ceiling of the room, which gives a uniform distribution of temperature. Air speed measuring devices were used, and the air speed was measured in the breathing zone. It was too little to be suitable for human breathing, which creates a state of discomfort with the possibility of increasing the temperature in the breathing zone.

In case II, the rate of airflow from the personal ventilation system to $5 \mathrm{l} / \mathrm{s}(10.6 \mathrm{cfm})$ and a speed of $0.6 \mathrm{~m} / \mathrm{s}$. After measuring the temperatures at the same altitudes and the corresponding locations of the poles inside the room, as shown in Table 6.

Table 6 Experimental results with PV air flow rate 51/s case II

\begin{tabular}{|l|l|l|l|}
\hline Height $(\mathrm{m})$ & Pole 1 & Pole 2 & Pole 3 \\
\cline { 2 - 4 } & Temperature ${ }^{\circ} \mathrm{C}$ & $\begin{array}{l}\text { Temperature } \\
{ }^{\circ} \mathrm{C}\end{array}$ & $\begin{array}{l}\text { Temperature } \\
{ }^{\circ} \mathrm{C}\end{array}$ \\
\hline 0 & 25.234 & 24.78 & 25.8 \\
\hline 0.4 & 24.865 & 23.689 & 24.423 \\
\hline 0.8 & 26.145 & 24.6 & 26 \\
\hline 1.1 & 25.674 & 25.2 & 25.63 \\
\hline 1.4 & 25.412 & 24.36 & 25 \\
\hline 1.8 & 24.319 & 23.347 & 24.2 \\
\hline
\end{tabular}

It was noticed a decrease in the room temperature in general with an increase in the air speed near the person, and the temperature becomes more uniform inside the room. The floor temperature was not the lowest but rather the temperature at the height of $0.4 \mathrm{~m}$ from the floor of the room is the lowest. The air diffuser is installed at a slightly lower height than the ceiling, which makes the air temperature near the ceiling cooler than the floor temperature. Been noted this clearly in the pole 1, pole 2, and pole 3 as the temperature at the height of 1.4 is higher than the temperature at the height of $1.8 \mathrm{~m}$ due to the proximity of thermocouple at the height of $1.8 \mathrm{~m}$ from the room ceiling (cold supply air). The air temperature and the speed of the air in the breathing zone (plane 1.1) were measured, and it was found that the velocity of air in contact with the person's face inside the room did not exceed $0.25 \mathrm{~m} / \mathrm{s}$. This is an ideal case suitable for thermal comfort for humans. The air velocity contact the face of the two-person was not equal. It was good for the person (2) and acceptable for the person (1). Because the increased the speed of the air to the acceptable level, it increased the temperature drop for the face and 
the human body. This condition is considered acceptable with regard to human comfort and the effectiveness of personal ventilation devices, but the air speed measured for the breathing zone of the person (1) was the lowest permissible value that may be inappropriate for the person sitting, so this conditions were evaluated as acceptable but not ideal.

The average room temperature that it decreased with an increase in the rate of air flowing from (ATD). This is explained by the fact that the cold air at a level of $0.4 \mathrm{~m}$ (plane 0.4 ) from the floor of the room was drawn in larger quantities and its supply at the level of $1.1 \mathrm{~m}$, which means that the personal ventilation device pulls the cold air and recycle it inside the room before it is taken out by return air grille.

In this case II, the airflow rate for the personal ventilation system (PV) is increased to $6 \mathrm{l} / \mathrm{s}(12.7 \mathrm{cfm})$, that is, at a speed of $0.7 \mathrm{~m} / \mathrm{s}$. The horizontal distance between (ATD) and the face of the sitting person is $50 \mathrm{~cm}$. The data of experimental temperature illustrated in tables (7). Fig. (9).

Table 7 Experimental results with PV air flow rate 61/s case II

\begin{tabular}{|c|c|c|c|}
\hline Height $(\mathrm{m})$ & Pole 1 & Pole 2 & Pole 3 \\
\cline { 2 - 4 } & Temperature ${ }^{\circ} \mathrm{C}$ & Temperature ${ }^{\circ} \mathrm{C}$ & Temperature ${ }^{\circ} \mathrm{C}$ \\
\hline 0 & 24.98 & 23.986 & 25 \\
\hline 0.4 & 23.886 & 22.843 & 23.9 \\
\hline 0.8 & 25.756 & 23.789 & 25.64 \\
\hline 1.1 & 24.632 & 25 & 24.876 \\
\hline 1.4 & 25.2 & 24.2 & 24 \\
\hline 1.8 & 23.896 & 22.7 & 23.647 \\
\hline
\end{tabular}

This figure shows the relation of air temperature with height through poles 1,2 , and 3 at $6 \mathrm{l} / \mathrm{s}$ flow rate for PV. In general, the decrease in temperature with the height of the office room is due to the effect of the cold air supply coming from the diffuser installed in the upper part of the room wall. The difference in temperature between the head and foot is obtained less than $2^{\circ} \mathrm{C}$, which is acceptable range as specified in ASHRAE standards. The lowest temperatures inside the room are noted at the level $0.4 \mathrm{~m}$ above the floor of the room inside the occupied zone, as a result of this level being devoid of heat sources. The air is intake from a height of $0.4 \mathrm{~m}$ and supplied to the breathing zone of the person. The measured air velocity in the breathing zone does not exceed 0.25 $\mathrm{m} / \mathrm{s}$, and for two-person ( 1 and 2 ), this case was better and more acceptable than previous cases .

The breathing zone, in this case, is characterized by a decrease in temperature with a good height of velocity of air permitted within limits recommended thermal comfort. The ceiling temperature is less than the floor temperature of the room because the air diffuser is installed near the ceiling. The air temperature starts to rise and then returns to decrease again due to the coming cold air currents from personal ventilation devices (ATD) as well as the air supply diffuser (MV device).

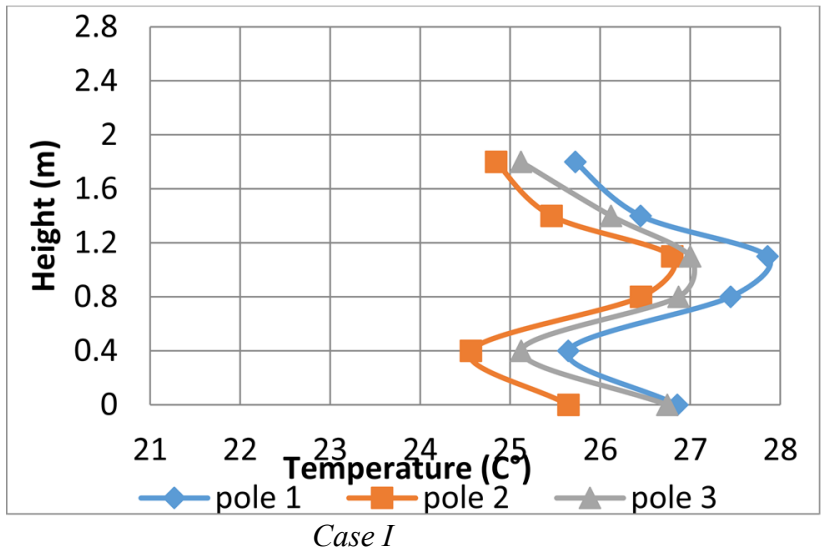

An experimentally measured temperature drop was observed at all the points specified on the three poles of the IV case, as show in Fig. (9). The temperature distribution became more uniform, which indicates an increase in indoor air quality (IAQ) and an improvement in thermal comfort inside the test room. This was better than experimental aspect. The air speed was measured experimentally in the breathing zone, that it did not exceed $0.25 \mathrm{~m} / \mathrm{s}$ for both persons ( 1 and 2 ). Also, the temperature in the breathing zone was measured for both person. The average temperature room was found to be less than the previous cases, and this is considered a good thing for the person in the office room, as these conditions increase the thermal comfort of the person, which means that the effectiveness of ventilation is excellent.

The air was supplied from (ATD) with a flow rate (7) $1 / \mathrm{s}$ (14.8 cfm) and a velocity $(0.8) \mathrm{m} / \mathrm{s}$. The average temperature inside the occupied zone was measured. A decrease in the temperatures inside the room, in general, was found with a reduction in the temperature in the breathing zone and an increase in the speed of the air within an breathing zone as shown Table 8.

Table 8 Experimental results with PV air flow rate 71/s ,case II

\begin{tabular}{|c|c|c|c|}
\hline \multirow{2}{*}{$\begin{array}{c}\text { Height } \\
(\mathrm{m})\end{array}$} & Pole 1 & Pole 2 & Pole 3 \\
\cline { 2 - 4 } & Temperature ${ }^{\circ} \mathrm{C}$ & Temperature ${ }^{\circ} \mathrm{C}$ & Temperature $\left.{ }^{\circ} \mathrm{C}\right)$ \\
\hline 0 & 24.3 & 23.86 & 24.63 \\
\hline 0.4 & 22.8 & 22.68 & 23.4 \\
\hline 0.8 & 24.963 & 23.745 & 25 \\
\hline 1.1 & 23.785 & 24.678 & 24.23 \\
\hline 1.4 & 24.56 & 23.874 & 23.56 \\
\hline 1.8 & 23 & 22.86 & 23.423 \\
\hline
\end{tabular}

Despite the decrease in the average temperature inside the test room and the breathing zone, the speed of air in contact with the person's face began to exceed the permissible limit, as it started ranging between 0.26 to 0.3 $\mathrm{m} / \mathrm{s}$. The airflow rate $7 \mathrm{l} / \mathrm{s}$ not appropriate in the case that the distance between the person and air terminal device is $0.5 \mathrm{~m}$.. Table 9 shows the temperature drop at the plane of $1.1 \mathrm{~m}$ with the increase in air flow rates from the personal ventilation systems

Table 9Experimental data in the breathing zone

\begin{tabular}{|c|c|c|c|}
\hline Case & T plane 1.1m & $\begin{array}{c}\text { U breathing zone } \\
\text { (m/s) }\end{array}$ & $\begin{array}{c}\text { Heat removal } \\
\text { effectiveness }\end{array}$ \\
\hline $\mathrm{I}(0 \mathrm{l} / \mathrm{s})$ & 26.7 & 0.1 to 0.12 & 0.8 \\
\hline $\mathrm{II}(5 \mathrm{l} / \mathrm{s})$ & 25.6 & 0.13 to 0.25 & 0.84 \\
\hline $\mathrm{II}(61 / \mathrm{s})$ & 24.8 & 0.24 to 0.25 & 0.89 \\
\hline $\mathrm{II}(71 / \mathrm{s})$ & 24.2 & 0.3 to 0.35 & 0.91 \\
\hline
\end{tabular}

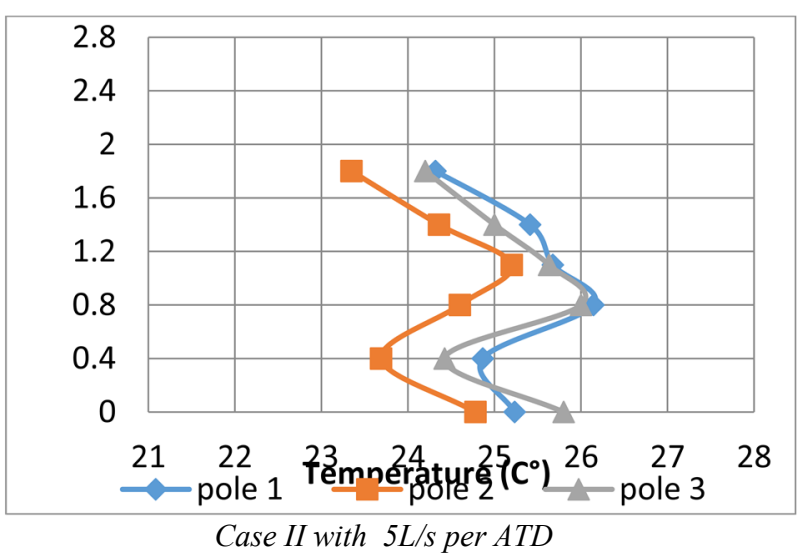




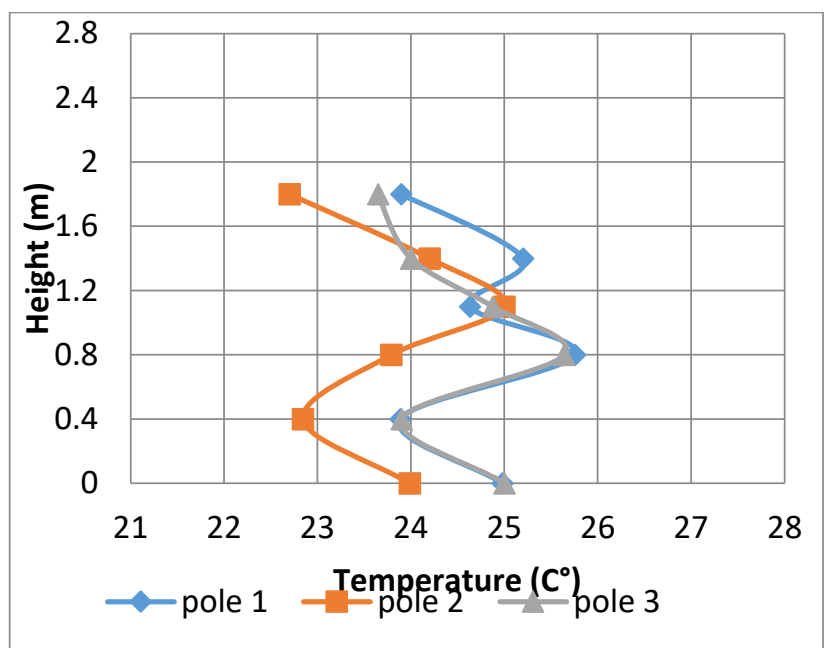

Case II with $6 L / s$ per ATD

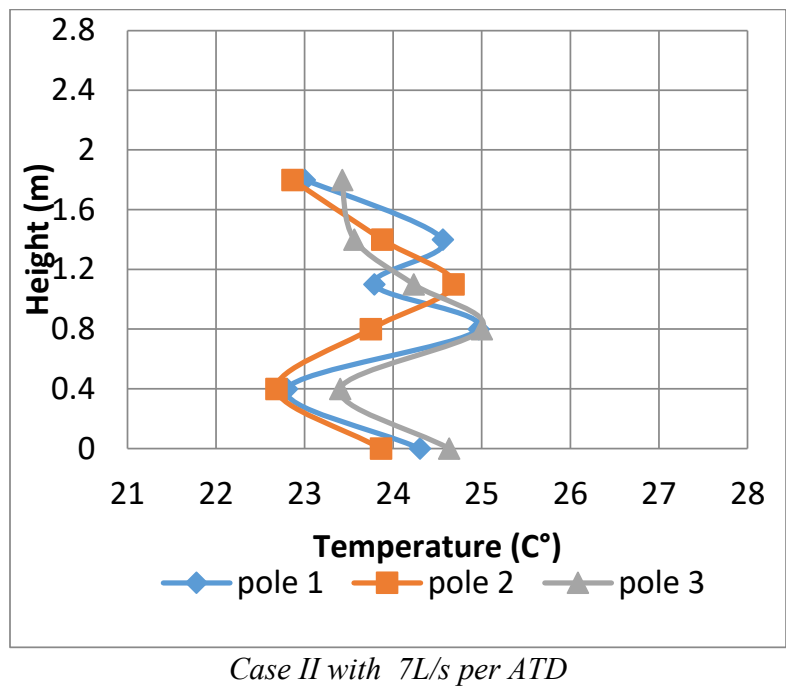

Case II with $7 L /$ s per ATD

Fig. 9 The relationship between altitude and temperature

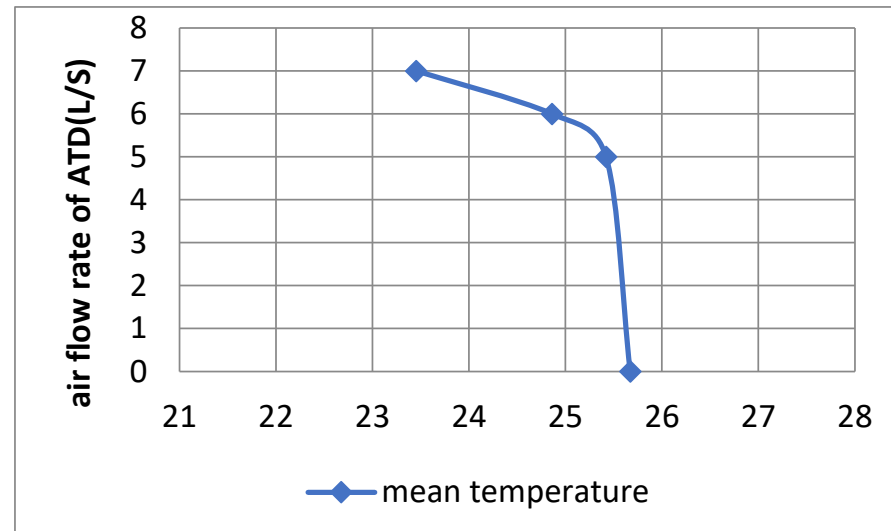

Fig. 10 Relationship between (mean temperature ) and (air flow rate of ATD)

\section{Numerical result}

Analysis of temperature distribution and air velocity of room for MV only

The test room model was simulated and modeled using CFD; Fig (12-a) shows the test chamber model and the locations of the poles inside room. Figs. (12-b) display numerically the contours of distribution of air temperature at different planes in the tested room for the MV system

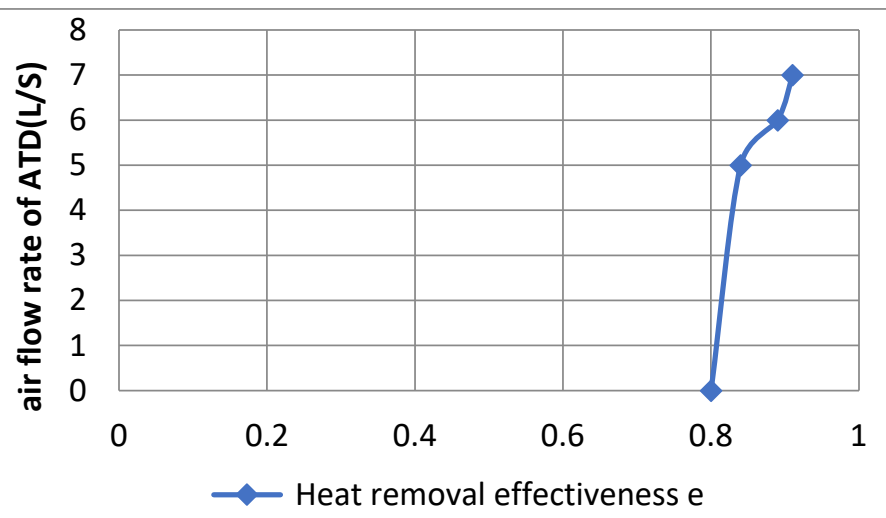

Fig. 11 the relationship between effectiveness and the airflow for personal ventilation (ATD)

only. The air temperature reaches $17^{\circ} \mathrm{C}$, the first time that air enters the room from the diffuser installed near the ceiling of the room (under the roof of the room). It is noted that the temperature begins to rise when increasing the horizontal distance between the diffuser and the air. The increase in temperature starts from $17^{\circ} \mathrm{C}$ until it reaches $23{ }^{\circ} \mathrm{C}$ within the (z-plane through the center of room $\mathrm{Z}=1.25 \mathrm{~m}$ ) of the middle of the room

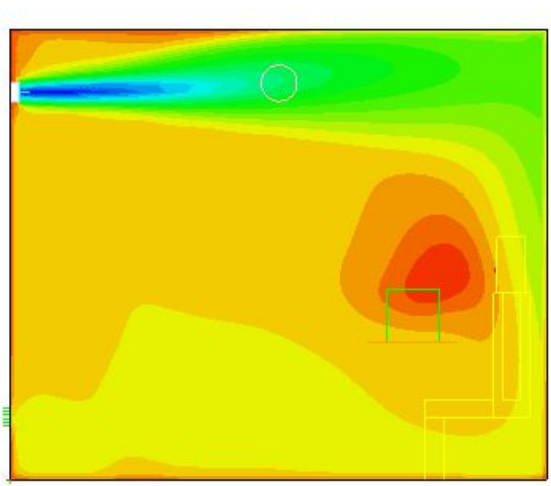

Temperature
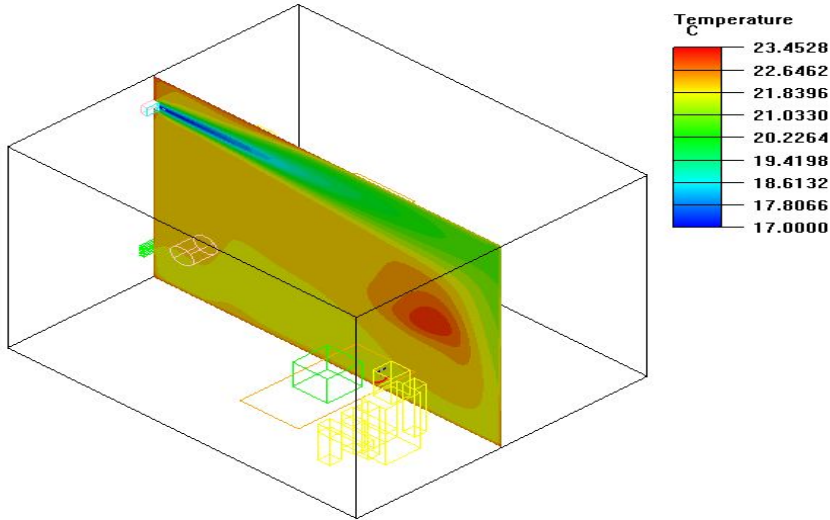

a- iso

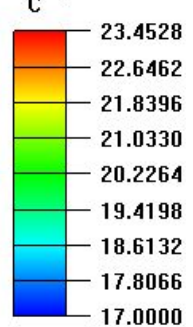

b- side

Fig. 12 Contour of air temperature in $\mathrm{z}$-plane at $\mathrm{z}=1.25 \mathrm{~m}$, for the case I 
The temperature contour in the z-plane through person (1) is shown in figure (13-a) and the temperature contour in the z-plane through person 2 is shown in figure(13-b) that the temperature reaches about $30^{\circ} \mathrm{C}$ near the human body and (PC) simulator. As a result of the difference in

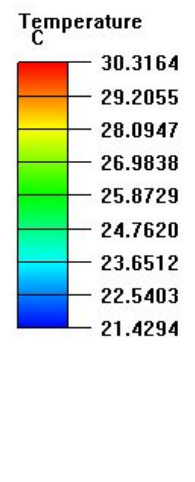

a-Person 1 temperature between the sources of heat and the air, the heat is transferred to the top in the form of thermal plumes by convection, and then the hotter air mixes again with the cold air coming from the outside with a temperature of $17^{\circ} \mathrm{C}$.
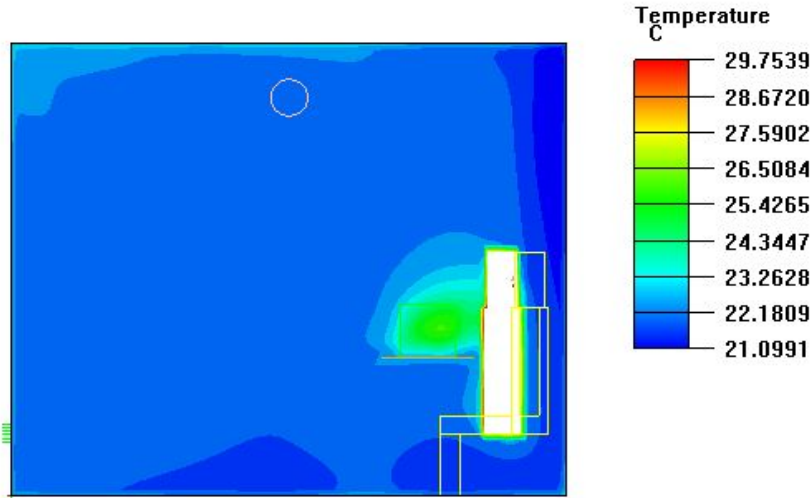

b-Person 2

Fig. 13 Contour of air temperature in z-plane through person no. land no. 2 within the office room for the case I

Observed and concluded through numerical contours as shown in Figs (12) and (13) there is a good uniformity in the temperature distribution of air in the room, but the air temperature in the breathing zone ranges between 24 to $26^{\circ} \mathrm{C}$ as it is considered an acceptable temperature, but it is not the best and most suitable for good human breathing and ideal thermal comfort. In the case of using a MV system, the air inside the room is supplied with high speed and high momentum, This method enables the air jet to overcome the buoyancy force generated from heat sources and reach further regions.

From numerical results, the Contour of velocity for case (I) is shown in Figs. (14)and(15) high values of air velocity are obtained from the supplied (ATD) in the upper region due to the location of the supply air duct in this zone. Fig. (16) presents streamlines flow patterns from the MV diffuser for case I. the air is supplied at $2.5 \mathrm{~m} / \mathrm{s}$ as a result of the high air speed and high momentum air circulation occurs in the room and as a result of the heat gain resulting from persons, computers, and the room's contents. As a result of the movement of air inside the room, the fresh cold air coming from the diffuser with the hot air inside the room gets mixing. The air is released through the air exit hole below the diffuser at the height of $0.3 \mathrm{~m}$ from the floor of the room, and the air exit speed is higher than the speed of entry to the room due to the small (Exhaust grill) compared to the air supply area Fig. (17) shows the air velocity vector for the predicted velocity vector plot for the (MV)system for case I. The turbulence model displays the calculated air velocity vector of the three poles for the cases studied. The flow configuration where the flow is separated in the middle of the room. A small portion

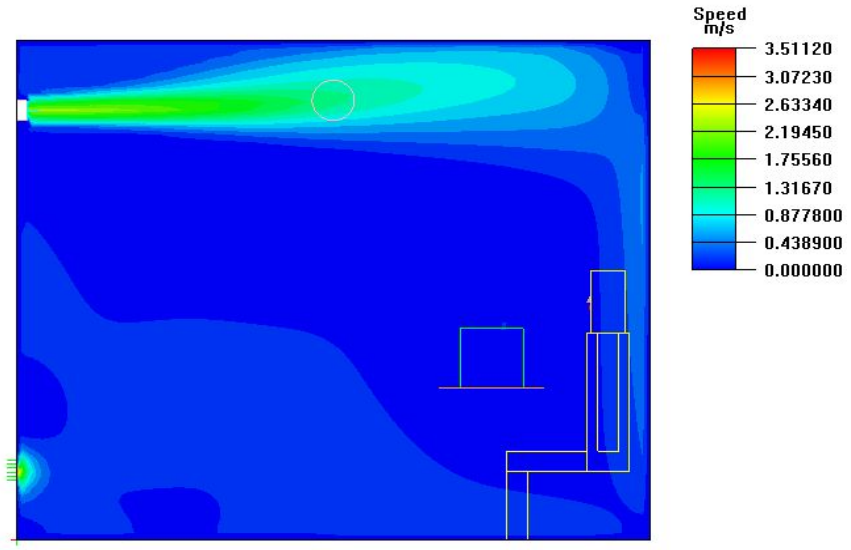

Fig. 14 Contour of airspeed magnitude $(\mathrm{m} / \mathrm{s})$ at the centers of the supply vents in case I collides the opposite wall and turns down, then a large part of the reverse flow is exhausted, and the other turns up toward the roof. This movement induces in the room creates a circulation zone at the center of the room. The cold air has a higher density than warmer air, and thus creates downward convective flows, then the warm air exits from the tested room by an exhaust grille: clockwise swirling and rotating flow near the objects. Through the numerical results, it is noticed that the average temperature for planes from 0 to $1.8 \mathrm{~m}$ decreases with the increase in the air flow rates from the personal ventilation system despite the remain the air temperature constant for both the personal ventilation system and the mixing ventilation system as shown in the Table 10 .

Table 10 Average temperatures for each planes parallel to the room

\begin{tabular}{|c|c|c|c|c|}
\hline \multicolumn{5}{|c|}{ floor } \\
\hline $\begin{array}{c}\text { Case } \\
\begin{array}{c}\text { Air flow rate of } \\
\text { PV }\end{array}\end{array}$ & 0 & 5 & 6 & 7 \\
\hline Plane $_{0}$ & 26.3 & 25.4 & 24.6 & 24.2 \\
\hline Plane 0.4 & 25.3 & 24.8 & 24.3 & 24.1 \\
\hline Plane 0.8 & 26 & 25.4 & 25.4 & 25.1 \\
\hline Plane 1.1 & 24.36 & 24.1 & 23.8 & 23.95 \\
\hline Plane 1.4 & 25.36 & 25 & 24.6 & 24.4 \\
\hline Plane 1.8 & 24.4 & 25.3 & 24.3 & 24.3 \\
\hline
\end{tabular}

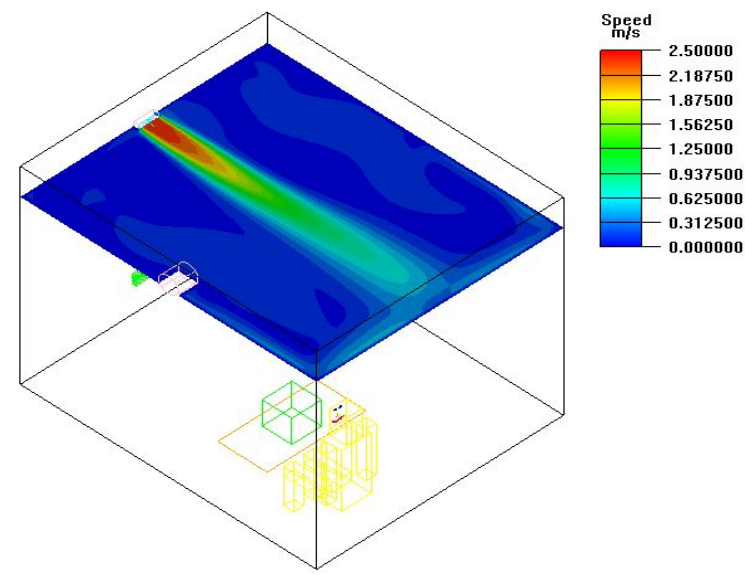

Fig. 15 The contour of airspeed magnitude $(\mathrm{m} / \mathrm{s})$ in $(\mathrm{y}-$ plane)within the office room for the case I 


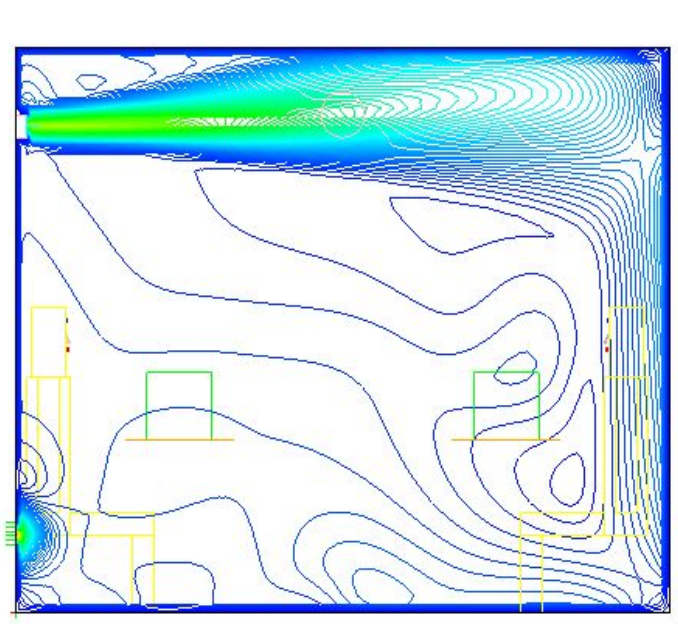

Fig. 16 the computed streamlines for MV only perspective view

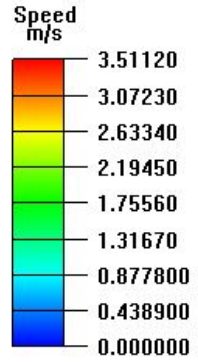

\section{Analysis of temperature distribution and air velocity of room for}

\section{PMV system:}

Figs(18) to (22). These figures also display numerically the contours of distribution of air temperature at planes in the tested room, where the temperature of the air increases from $17^{\circ} \mathrm{C}$ closely to the supply terminal and reaches about $31^{\circ} \mathrm{C}$ near the person and $\mathrm{PC}$-simulator. Despite the use of the same flow rates for PV systems for both persons, it was found that the velocity of air in contact with the person's face within the breathing zone is different with different air flow rate from (ATD) where the best result with $61 / \mathrm{s}$ from (ATD) because the air velocity does not

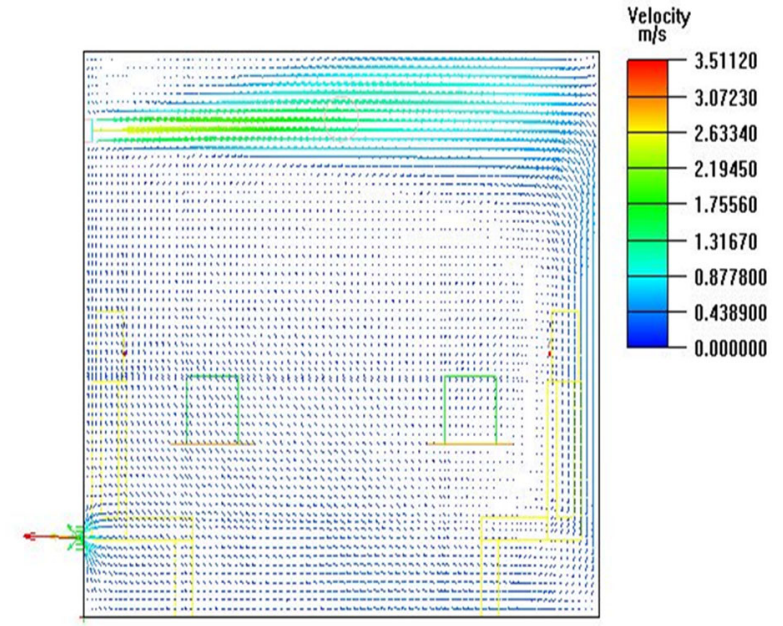

Fig. 17 the predicted velocity vector plot in the middle (Zplane $)(Z=1.25 \mathrm{~m})$ for the $\mathrm{MV}$ ventilation system.
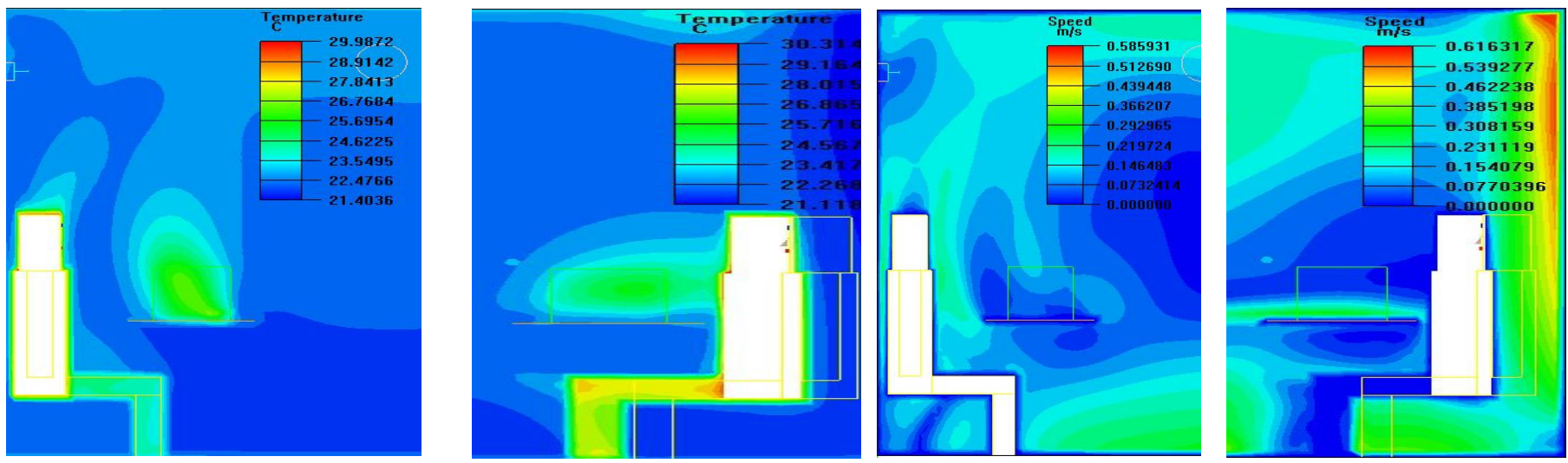

Fig. 18 Contour of airspeed and air temperature show breathing zone case I
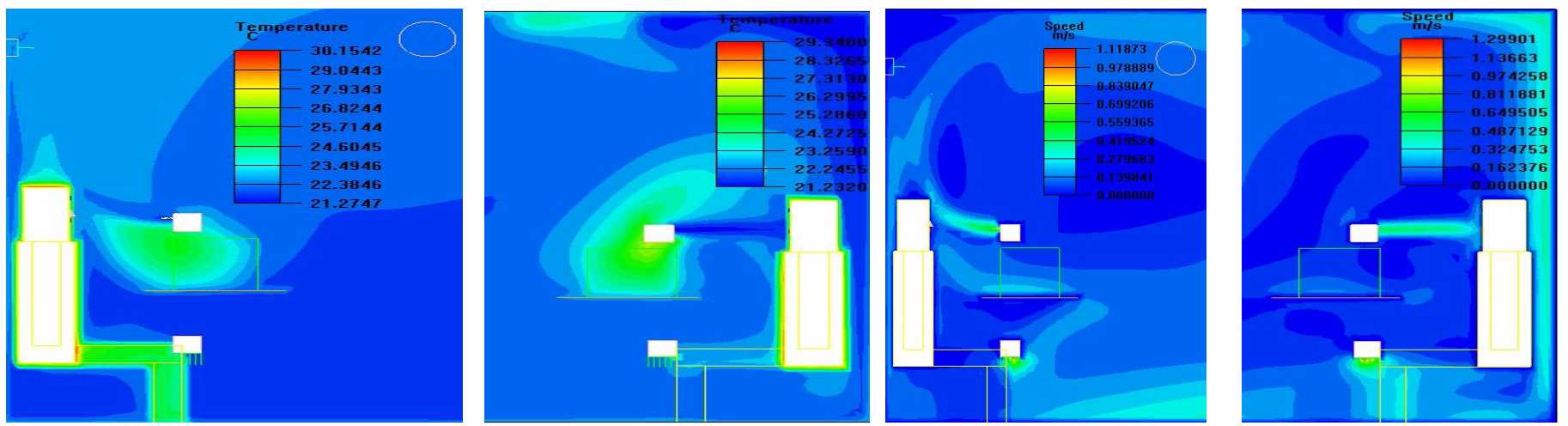

Fig. 19 Contour of airspeed and air temperature show breathing zone, Case II 51/s 

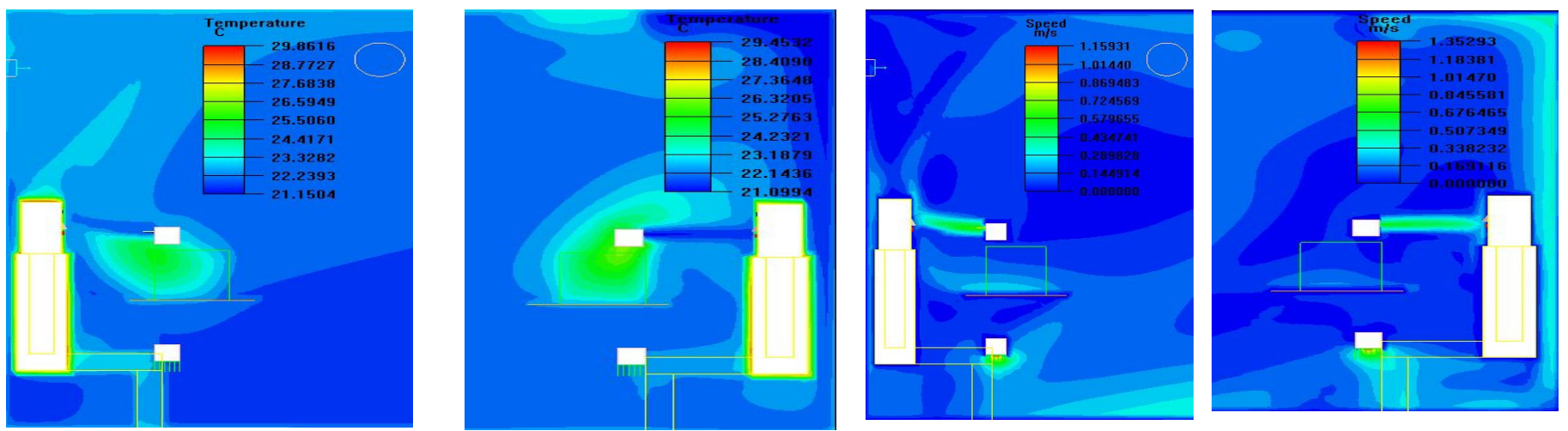

Fig. 20 Contour of airspeed and air temperature show breathing zone, CaseII,61/s
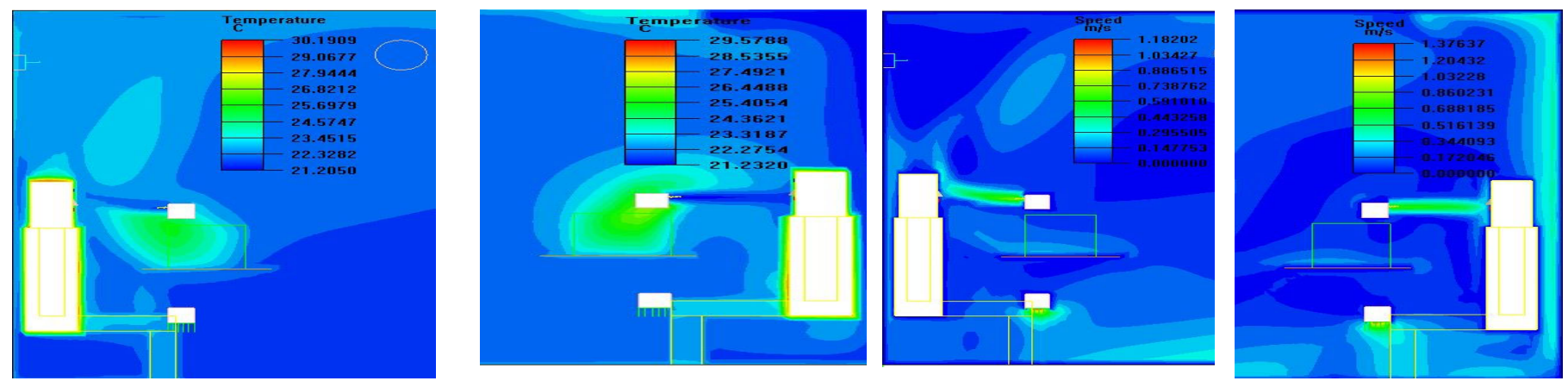

Fig. 21 Contour of air speed and air temperature show breathing zone, Case II,71/s

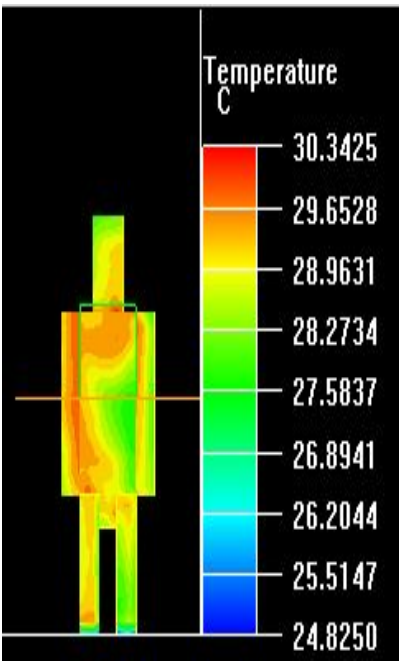

I

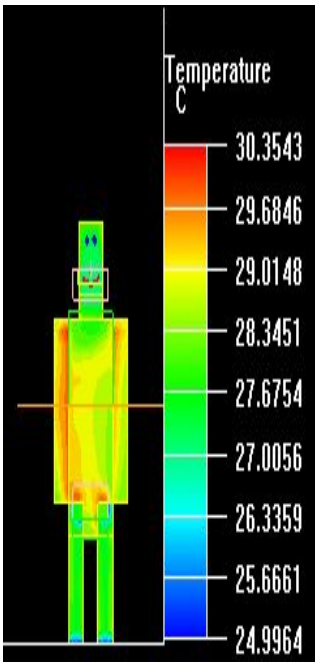

$\mathrm{II}, 5 \mathrm{I} / \mathrm{s}$

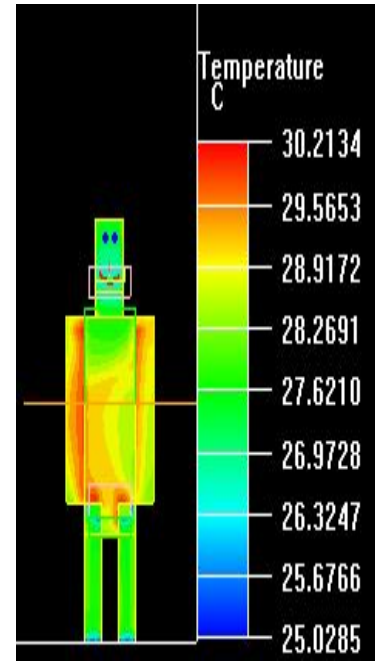

$\mathrm{II}, 6 \mathrm{l} / \mathrm{s}$

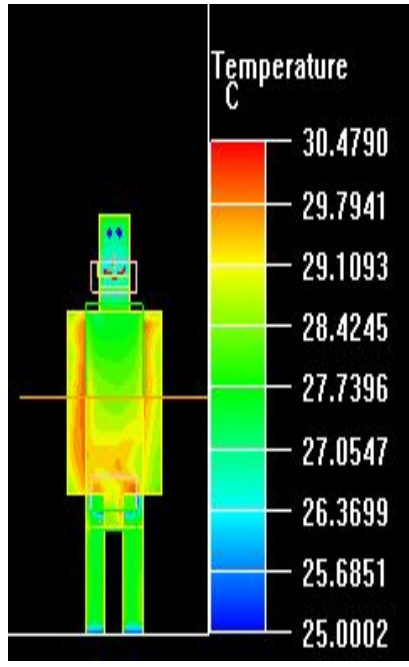

II,7l/s

Fig. 22 Contour of air temperature at object face of a person

Figs. (23) to (26) display numerically the contours mean age of air, where it is noticed that the mean age of the air would be less in the breathing zone and entire room in the case of using PV systems, which gives an explanation that the air in the breathing zone is renewed more quickly than if not use the PV system and this leads to increased thermal comfort for a person. Also, all numerical data regarding the mean air age were mentioned in Table 11. It is conclude from the numerical values that the increase in the speed of the air supply from (ATD) will reduce the temperature in the breathing zone, mean temperature of the room and will reduce the mean age of the air in the breathing zone and in-room. which means an increase in IAQ and the improvement of thermal comfort, but this increase in airspeed should do not reach the level of inconvenience for space occupants if the air velocity should not exceed $0.25 \mathrm{~m} / \mathrm{s}$. The case II is considered the best case at an air flow rate of $61 / \mathrm{s}$ as shown in the Table 12 .

Table 11 numerical value of the mean age of air

\begin{tabular}{|c|c|c|c|c|}
\hline \multirow{2}{*}{ cases } & I & \multicolumn{3}{|c|}{ III } \\
\cline { 3 - 5 } & & $\begin{array}{c}5 \mathrm{I} / \mathrm{s} \text { per } \\
\text { ATD }\end{array}$ & $\begin{array}{c}6 \mathrm{6I} / \mathrm{s} \text { per } \\
\text { ATD }\end{array}$ & $\begin{array}{c}\text { 7l/s per } \\
\text { ATD }\end{array}$ \\
\hline $\begin{array}{c}\text { Mean age of air } \\
\text { (s) }\end{array}$ & 369.82 & 303.62 & 294.64 & 288.42 \\
\hline
\end{tabular}



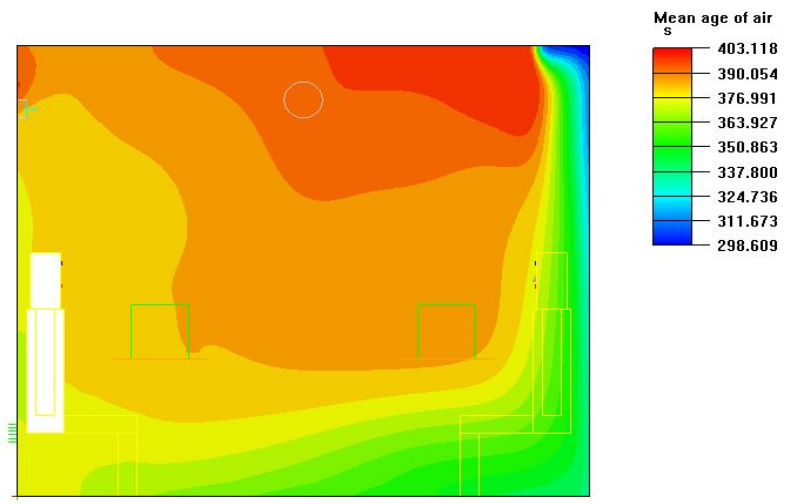

Fig.23 Contour of mean age air through persons 1,2 for Case I

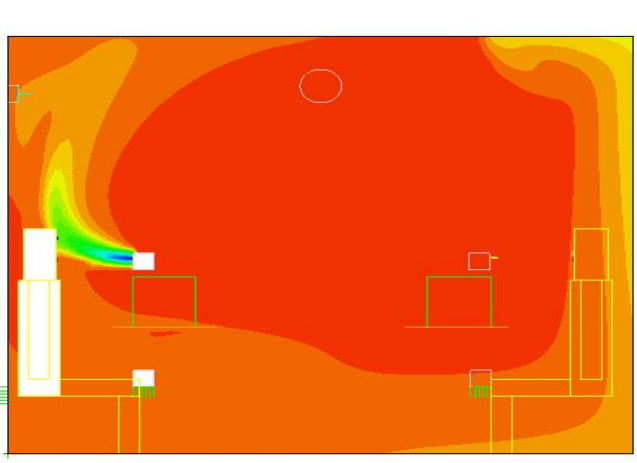
Mean age of air

\section{S 327.973}

\begin{tabular}{|c|r|}
\hline & 327.973 \\
\hline & 286.976 \\
\hline & 245.980 \\
& 204.983 \\
\hline & $\mathbf{1 6 3 . 9 8 7}$ \\
\hline & $\mathbf{1 2 2 . 9 9 0}$ \\
\hline & $\mathbf{8 1 . 9 9 3 3}$ \\
\hline & $\mathbf{4 0 . 9 9 6 6}$ \\
\hline & $\mathbf{0 . 0 0 0 0 0 0}$ \\
\hline
\end{tabular}

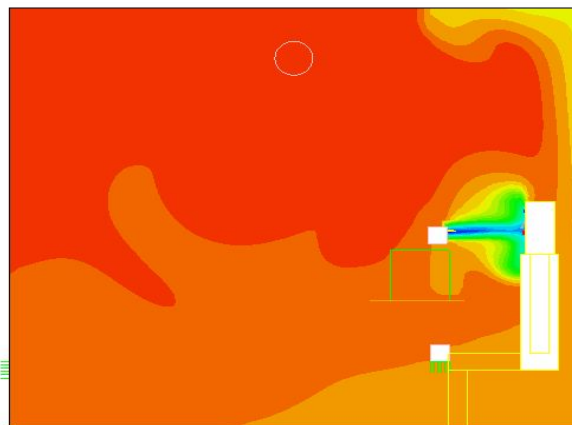

Mean age of air

$\mathrm{s}-\mathbf{4 0 1 . 2 8 5}$
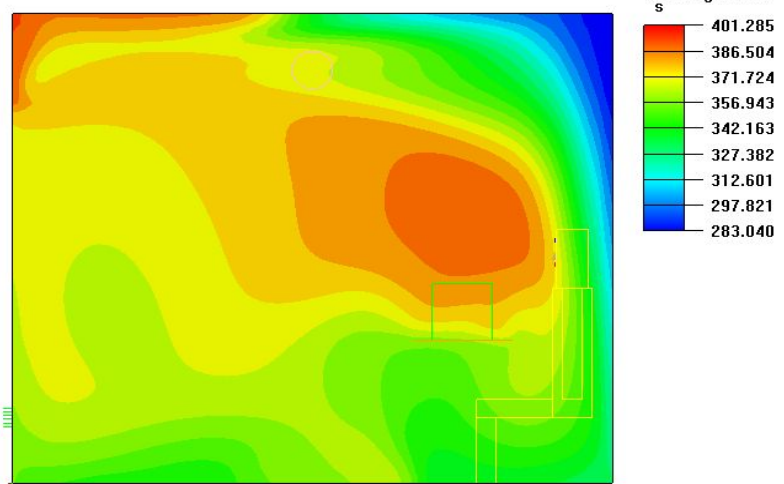

Fig. 24 Contour of mean age air through persons 1,2 for Case II Mean age of air
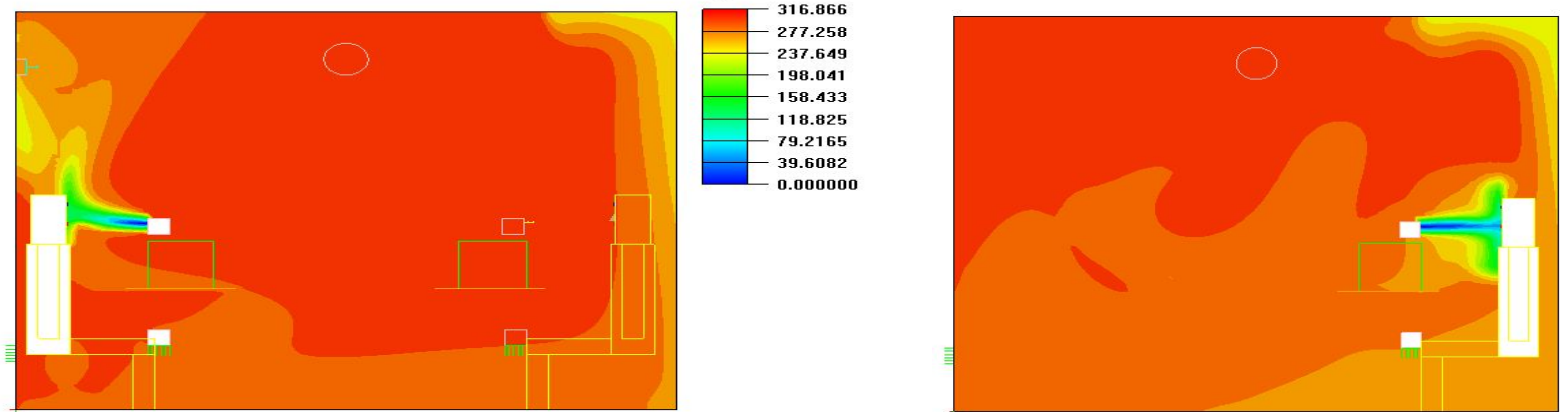

Mean age of air

s 329.497 329.497
-288.310 247.123 $\begin{array}{r}\mathbf{2 0 5 . 9 3 6} \\ -\mathbf{1 6 4 . 7 4 9} \\ \hline\end{array}$ 123.561 $\mathbf{8} 2.3743$
-41.1871 0.000000

Fig. 25 Contour of mean age air through persons 1,2 for Case II

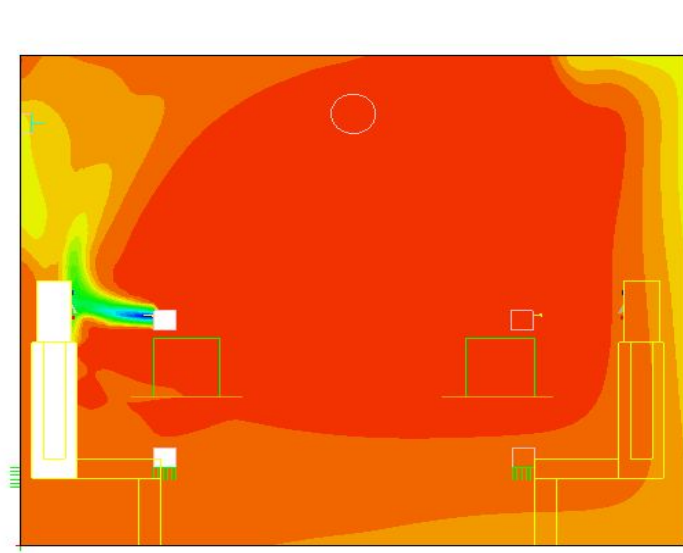

Mean age of air

\begin{tabular}{|r|r|}
\hline & 313.236 \\
\hline & 274.082 \\
\hline & 234.927 \\
\hline & 195.773 \\
\hline & 156.618 \\
\hline & 117.464 \\
\hline & 78.3090 \\
\hline & $\mathbf{3 9 . 1 5 4 5}$ \\
\hline & $\mathbf{0 . 0 0 0 0 0 0}$ \\
\hline
\end{tabular}

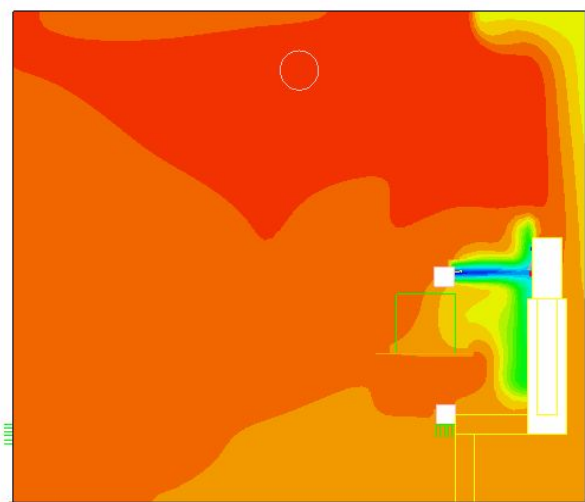

Fig. 26 Contour of mean age air through persons 1,2 for Case II 
Table 12: numerical values of ADPI and effectiveness $\left(\varepsilon_{t}\right)$ temp. for each ventilation type

\begin{tabular}{|c|c|c|c|c|}
\hline Ventilation devices used & Only mixing & \multicolumn{3}{|c|}{ MV combined with $P V$} \\
\hline Case & Case I & \multicolumn{3}{|c|}{ Case II } \\
\hline Air flow rate from PV device & -------------- & $5 l / s$ & $6 l / s$ & $7 l / s$ \\
\hline ADPI & 66.471 & 68.23 & 70.631 & 71.8 \\
\hline Effectiveness & 0.86 & 0.86 & 0.9 & 0.91 \\
\hline
\end{tabular}

\section{Comparison Between pilot and Numerical Results}

In this part of this study, a comparison will be made between experimental results and numerical results, knowledge of the difference and deviation in those results, by calculating the percentage of error obtained in this study, where the disturbance model was adopted (RNG $\mathrm{K}-\varepsilon)$. The comparison between the numerical and experimental results will be explained in the following parts. Fig. (27) show the comparison between the experimental and numerical results of the six cases where the temperature for pole one inside the room was calculated experimentally and numerically, and the difference in values was found as shown in the following figures. The average deviation between the experimental and numerical values as shown in Table 13.

Table 13 The average deviation between the experimental and

\begin{tabular}{|c|c|l|l|c|}
\hline numerical for temperature \\
\hline No. case & $\mathrm{I}$ & \multicolumn{3}{c|}{ II } \\
\hline Air flow rate of PV & & $5 \mathrm{l} / \mathrm{s}$ & $6 \mathrm{l} / \mathrm{s}$ & $7 \mathrm{~s}$ \\
\hline $\begin{array}{c}\text { Average } \\
\text { deviation\% }\end{array}$ & $8 \%$ & $4.15 \%$ & $4.68 \%$ & $4.5 \%$ \\
\hline
\end{tabular}

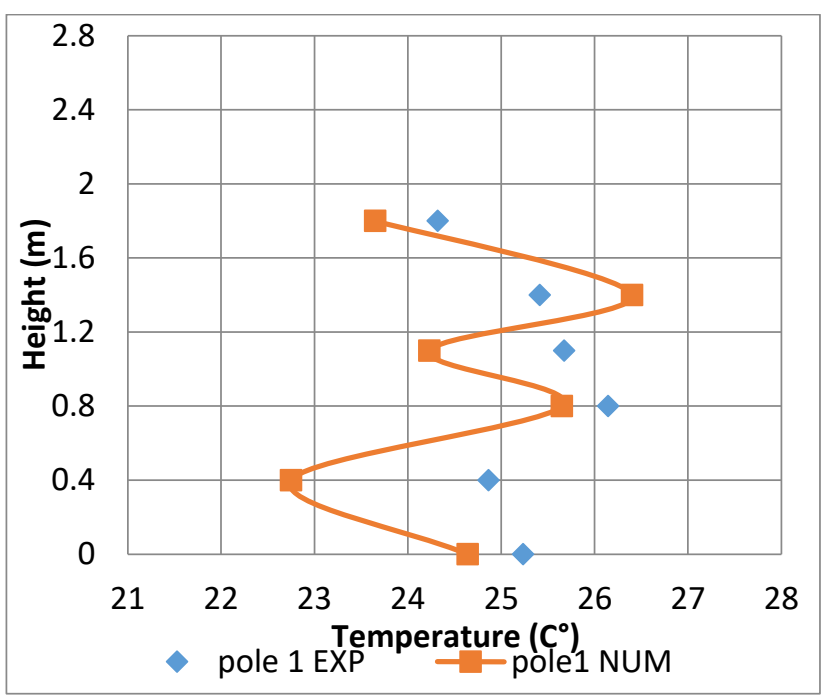

$\rightarrow$ pole 1 EXP $\quad$ pole1 NUM

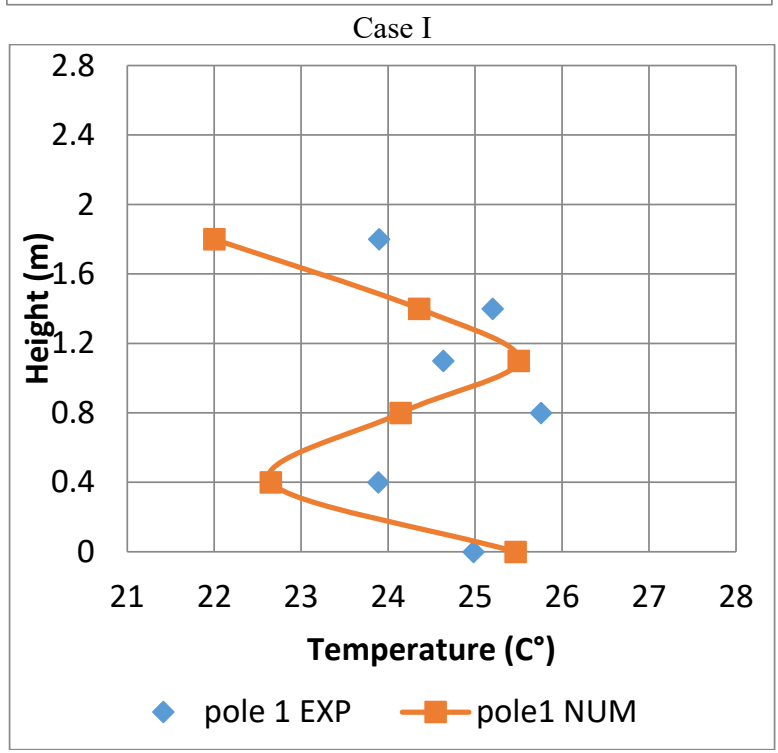

Case II, 61/s per ATD
Case II, 51/s per ATD

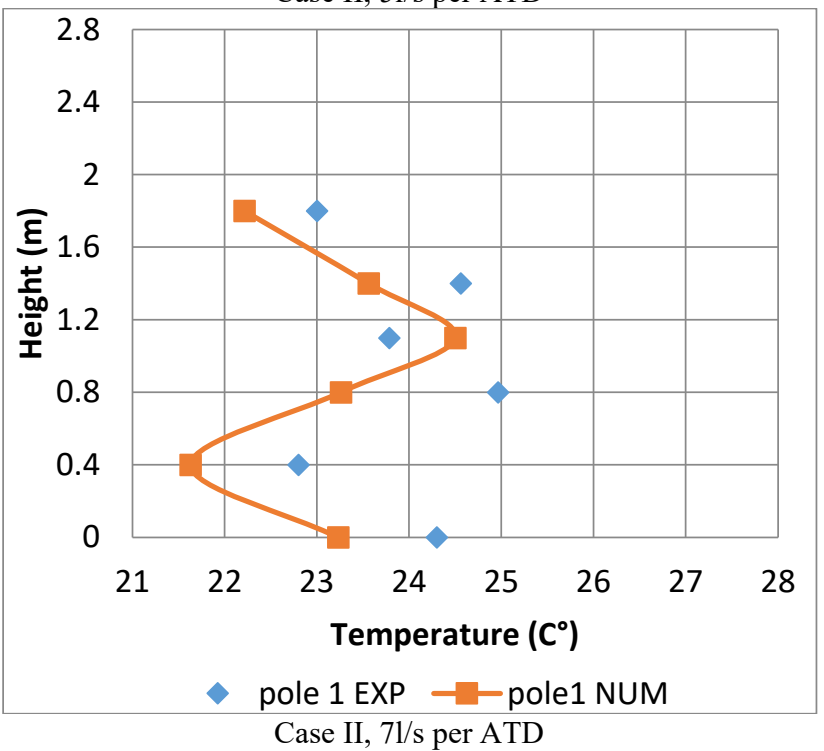

Fig. 27 Comparison between predicted and experimental results 


\section{Conclusions}

The present work focuses on the numerical analysis of air quality and human thermal comfort in the office room by adopting MV and PV system under the Iraqi climate. Where conclusions of this study can be summarized:

1- Using a personal ventilation system in combination with mixing ventilation system increases the indoor air quality.

2- At a constant supply air temperature, the quality of the inhaled air in the breathing zone increases with the increase in the supply air flow rates from (ATD).

3- Numerical and experimental results at combined MV with PV devices give acceptable result at the air volume flow rate of $61 / \mathrm{s}$.

4- It has been proven that the supply of fresh cold and clean air to the occupants breathing zone by using PMV system will improve greatly human thermal comfort, PAQ, and inhaled air quality.

5- The turbulence model (RNG k-e) gives the best compatibility between experimental and numerical results in verification cases by predicting thermal behavior and air flow patterns for $\mathrm{MV}$ and PV devices in simulated office rooms.

6- Through numerical results comparisons, ADPI values were calculated for all cases. It was found that the highest value $(70.631 \%)$ and with respect to $\left(\varepsilon_{t}\right)$, the maximum value $(0.9)$ was obtained from case II. The case II in $(6 \mathrm{l} / \mathrm{s}$ per ATD) is considered the best case, because the air velocity in the breathing area is more comfortable than its speed in case II when (7 1/sper ATD).

\section{Nomenclature}

\begin{tabular}{|c|c|}
\hline A & Surface Area for Wall $\left(\mathrm{m}^{2}\right)$ \\
\hline $\mathrm{C}_{\mathrm{p}}$ & Specific heat of the air at pressure constant $(\mathrm{kJ} / \mathrm{kg} . \mathrm{K})$ \\
\hline $\mathrm{C} 1 \varepsilon, \mathrm{C} 2 \varepsilon$ & Coefficient in the specific dissipation rate \\
\hline $\mathrm{D}$ & Diameter $(m)$ \\
\hline$d x d y d z$ & Control volume (m) \\
\hline G & Gravitational acceleration $\left(\mathrm{m} / \mathrm{s}^{2}\right)$ \\
\hline $\mathrm{N}$ & Total number of draft temperature points measured \\
\hline$P$ & Pressure $\left(\mathrm{N} / \mathrm{m}^{2}\right)$ \\
\hline Q & Heat transfer through the wall. (W) \\
\hline St & Source term for the rate of thermal energy $(\mathrm{J} / \mathrm{kg})$ \\
\hline $\mathrm{T}$ & Temperature ${ }^{\circ} \mathrm{C}$ \\
\hline $\mathrm{u}, \mathrm{v}, \mathrm{w}$ & Component of speed in $\mathrm{x}, \mathrm{y}$ and $\mathrm{z}$-directions $(\mathrm{m} / \mathrm{s})$ \\
\hline ui,j,k & Speed at cell $(\mathrm{i}, \mathrm{j}, \mathrm{k})(\mathrm{m} / \mathrm{s})$ \\
\hline $\mathrm{x}, \mathrm{y}, \mathrm{z}$ & Cartesian coordinates $(\mathrm{m})$ \\
\hline $\mathrm{Vx}$ & Local air speed $(\mathrm{m} / \mathrm{s})$ \\
\hline Vroom & Volume of room $(\mathrm{m} 3)$ \\
\hline$Q_{\mathrm{s}}$ & Design flow rate of the supply air (1/s) \\
\hline $\mathrm{q}_{\mathrm{ex}}$ & Cooling load for the heat conduction (W) \\
\hline $\mathrm{q}_{1}$ & Cooling load for the overhead lighting(W) \\
\hline qoe & Cooling load for occupant, desk and equipment (W) \\
\hline $\mathrm{Q}_{\mathrm{t}}$ & Total heat transfer $(\mathrm{W})$ \\
\hline $\mathrm{T}_{\mathrm{av}}$ & Average room temperature ${ }^{\circ} \mathrm{C}$ \\
\hline $\mathrm{Te}$ & Exhaust Air Temperature ${ }^{\circ} \mathrm{C}$ \\
\hline $\mathrm{T}_{\mathrm{m}}$ & Outlet design temperature ${ }^{\circ} \mathrm{C}$ \\
\hline $\mathrm{T}_{\mathrm{o}}$ & Outlet temperature ${ }^{\circ} \mathrm{C}$ \\
\hline $\mathrm{T}_{\mathrm{x}}$ & Local temperature ${ }^{\circ} \mathrm{C}$ \\
\hline $\mathrm{T}_{\mathrm{sp}}$ & Setup (design) temperature. ${ }^{\circ} \mathrm{C}$ \\
\hline
\end{tabular}

$\begin{array}{ll}\text { Greek Symbols } \\ \rho & \text { Air density }(\mathrm{kg} / \mathrm{m} 3) \\ \varepsilon & \text { Turbulent energy dissipation rate. }(\mathrm{J} / \mathrm{kg} . \mathrm{s}) \\ \sigma & \text { Prandtl or Schmidt number } \\ \Sigma \mathrm{k} & \text { Model constant } \\ \Sigma \varepsilon & \text { Model constant } \\ \Omega & \text { Specific dissipation rate }(1 / \mathrm{s}) \\ \Gamma & \text { Diffusion coefficient }\left(\mathrm{m}^{2} / \mathrm{s}\right) \\ \mu_{\mathrm{t}} & \text { Turbulent viscosity }\left(\mathrm{N} . \mathrm{s} / \mathrm{m}^{2}\right) \\ \Omega & \text { Rotation speed }(\mathrm{rad} / \mathrm{s}) \\ \Delta \mathrm{Thf} & \text { The difference in temperature from head to foot level. }{ }^{\circ} \mathrm{C} \\ \alpha \mathrm{k}, \alpha \varepsilon & \text { Coefficient in the specific dissipation rate } \\ \varepsilon_{\mathrm{t}} & \text { Effectiveness temperature } \\ \mathrm{T}_{\mathrm{t}} & \text { Turbulent Reynolds stress }\end{array}$

$\begin{array}{ll}\text { Sub-Scripts } \\ \text { av. } & \text { Average } \\ \text { c } & \text { Correct } \\ \text { e } & \text { Exhaust Air } \\ \text { ex } & \text { External } \\ \mathrm{f} & \text { Floor } \\ \text { hf } & \text { Head to foot level. } \\ \mathrm{H} & \text { Hydraulic } \\ \mathrm{I} & \text { Inside } \\ \mathrm{i}, \mathrm{j}, \mathrm{k} & \text { Location of point in a Cartesian grid } \\ \mathrm{l} & \text { Overhead light }\end{array}$

\section{Abbreviations}

$\begin{array}{ll}\text { ACH } & \text { Change of air per hour } \\ \text { ADPI } & \text { Air Distribution Performance Index } \\ \text { ASHRAE } & \text { American Society for Heating, Refrigeration, and } \\ \text { Air Conditioning Engineers } \\ \text { CFD } & \text { Computational Fluid Dynamics } \\ \text { PV } & \text { Personalized ventilation } \\ \text { PMV } & \text { Personal-mixing Ventilation } \\ \text { FVM } & \text { Finite Volume Method } \\ \text { EDT } & \text { Effective Draft Temperature } \\ \text { IAQ } & \text { Indoor air quality } \\ \text { MV } & \text { Mixing Ventilation } \\ \text { RNG } & \text { Re-Normalization Group } \\ \text { SBS } & \text { Sick Building Syndrome } \\ \text { ATD } & \text { Air terminal device } \\ \text { PAQ } & \text { Perceived air quality } \\ \text { DV } & \text { Displacement Ventilation }\end{array}$

\section{REFERENCES}

Al-Assaad, Douaa, Nesreen Ghaddar, and Kamel Ghali. "Performance of Mixing Ventilation System Coupled With Dynamic Personalized Ventilator for Thermal Comfort." ASME 2017 Heat Transfer Summer Conference. American Society of Mechanical Engineers Digital Collection, pp. 1-7, 2017. http://dx.doi.org/10.1115/ht2017-4747

Awbi, Hazim B. Ventilation of buildings, Second Edition, Taylor \& Francis, London; 536 Pages, 2003.

Awbi, Hazim B. Ventilation systems: design and performance. Routledge, 464 Pages, 2007. 
Awbi, Hazim B. "Ventilation for good indoor air quality and energy efficiency." Energy Procedia 112, 277-286, 2017. http://dx.doi.org/ $\underline{10.1016 / j . e g y p r o .2017 .03 .1098}$

Cermak, R., Melikov, A., Forejt, L., \& Kovar, O. "Performance of personalized ventilation in conjunction with mixing and displacement ventilation" Hvac\&R Research 12.2, 295-311, 2006. http://dx.doi.org/10.1080/10789669.2006.10391180

Chen, Huijuan. Experimental and numerical investigations of a ventilation strategy-impinging jet ventilation for an office environment. Diss. Linköping University Electronic Press, 2014. http://dx.doi.org/ 10.3384/diss.diva-106483

Douaa Al Assaad, Kamel Ghali, Nesreen Ghaddar, Carine Habchi "Mixing ventilation coupled with personalized sinusoidal ventilation: Optimal frequency and flow rate for acceptable air quality." Energy and Buildings 154, 569-580, 2017.

http://dx.doi.org/10.1016/j.enbuild.2017.08.090

ElMaghraby, Hossam A., "Numerical Simulation for Thermal Comfort using Conditioned Air through Mixing and Personalized Ventilation Systems in Field Environmental Chamber (FEC)."2014.

http://dx.doi.org/10.13140/RG.2.2.10982.22084

Iraqi cooling code, 2012.

Jassim Hussein M., Ali Farooq H., Al-Amir Qusay R., Hamzah Hameed K., Waheed Khafaji Salwan Obaid, "Entropy Generation Analysis of a Natural Convection inside a Sinusoidal Enclosure with Different Shapes of Cylinders," Frontiers in Heat and Mass Transfer (FHMT), 12, 22, 2019. http://dx.doi.org/10.5098/hmt.12.22

Kaczmarczyk, J., Melikov, A. K., \& Fanger, P. O, Human response to personalized ventilation and mixing ventilation. Indoor Air, 14(Suppl. 8), 14, 17-29, 2004. http://dx.doi.org/10.1063/1.2975972

Katramiz, E., Al Assaad, D., Ghaddar, N., and Ghali, K., "The effect of human breathing on the effectiveness of intermittent personalized ventilation coupled with mixing ventilation." Building and Environment : 106755, 2020

http://dx.doi.org/10.1016/j.buildenv.2020.106755
Kroner, Walter M. "Environmentally responsive workstations and officeworker productivity." ASHRAE Transactions 100.2, 750-755, 1994. doi:100.2.750 755. http://dx.doi.org/100.2.750 755

Melikov, Arsen Krikor. "Personalized ventilation." Indoor air 14, 157 167, 2004. http://dx.doi.org/10.1111/j.1600-0668.2004.00284.x

Melikov, Arsen K. "Human body micro-environment: The benefits of controlling airflow interaction." Building and Environment 91, 70-77, 2015. http://dx.doi.org/10.1016/j.buildenv.2015.04.010

Mohammed, Hyder. A theoretical study of a cold air distribution system with different supply patterns. Diss. M. Sc Thesis, University of Technology, Iraq, 2013.

Olesen, Bjarne W. "The philosophy behind EN15251: Indoor environmental criteria for design and calculation of energy performance of buildings." Energy and Buildings 39.7, 740-749, 2007.

http://dx.doi.org/10.1016/j.enbuild.2007.02.011

Peter V. Nielsen, Niels Møller Bartholomaeussen, Ewa Jakubowska, Hao Jiang "Chair with integrated personalized ventilation for minimizing cross infection." The International Conference on Air Distribution in Rooms, Proceedings of Roomvent 2007.

ISBN:9789529989805

Van Hooff, T., and B. Blocken. "Mixing ventilation driven by two oppositely located supply jets with a time-periodic supply velocity: A numerical analysis using computational fluid dynamics." Indoor and Built Environment: 1420326X19884667, 2019. http://dx.doi.org/10.1177/1420326x19884667

Yakoob, Mahdi, Alamir,"Evaluation of Air Exchange Efficiency in Rooms with Personal Ventilation in Conjunction with Displacement Ventilation Systems", International Journal of Mechanical \& Mechatronics Engineering IJMME-IJENS Vol:19 No:06, 2020.

Zeng, Qingfan, and Rongyi Zhao. "Prediction of perceived air quality for personalized ventilation systems." Tsinghua Science and Technology 10.2, 227-232, 2005. http://dx.doi.org/10.1016/s1007-0214(05)70059-6

Zhao, W., Kilpeläinen, S., Kosonen, R., Jokisalo, J., Lestinen, S., \& Mustakallio, Thermal environment and ventilation efficiency in a simulated office room with personalized micro-environment and fully mixed ventilation systems. Building and Environment, 188, 107445, 2021. http://dx.doi.org/10.1016/j.buildenv.2020.107445 